\title{
EVOLUTION AND APPLICATION OF URBAN WATERSHED MANAGEMENT PLANNING
}

\author{
Melissa L. Mika
}

Thesis submitted to the faculty of the Virginia Polytechnic Institute and State University in partial fulfillment of the requirements for the degree of

Master of Science
In
Civil Engineering

\author{
Randel L. Dymond, Chair \\ Clayton C. Hodges \\ Kevin D. Young
}

December 18, 2017
Blacksburg, VA

Keywords: watershed management, master planning, urban municipality, adaptive management, stormwater 


\title{
EVOLUTION AND APPLICATION OF URBAN WATERSHED MANAGEMENT PLANNING
}

\author{
Melissa L. Mika
}

\begin{abstract}
ACADEMIC ABSTRACT
The development of Watershed Management Plans (WMPs) in urban areas aids municipalities in allocating resources, engaging the public and stakeholders, addressing water quality regulations, and mitigating issues related to stormwater runoff and flooding. In this study, 63 urban WMPs across the nation were reviewed to characterize historical approaches and identify emerging trends in watershed planning. Planning methods and tools were qualitatively evaluated, followed by statistical analyses to identify correlations between planning factors. Plans developed by a municipality or consultant were correlated to higher occurrences of hydrologic modeling and site-specific recommendations, and lower occurrences of characterizing social watershed factors. Trends in the use and selection of hydrologic, hydraulic, and pollutant load models were identified, specifically in the past decade. Project prioritization was found to increasingly focus on feasibility in implementation. Additional qualitative trends identified include an increased focus on water quality and interdisciplinary studies, public participation, responsiveness to water quality regulations, and risk aversion. The study concludes by envisioning future watershed planning trends. This state of the practice review of planning efforts, innovation in implementation, and the adoption of emergent technologies will aid future planners in employing current tools and strategies in the development of new WMPs.
\end{abstract}




\title{
EVOLUTION AND APPLICATION OF URBAN WATERSHED MANAGEMENT PLANNING
}

\author{
Melissa L. Mika
}

\section{PUBLIC ABSTRACT}

Watershed-based management has long been used as the preferred approach for protection of water resources at a hydrologic, ecological, and social level. The development of Watershed Management Plans (WMPs) in urban areas aids municipalities in allocating resources, engaging the public and stakeholders, addressing water quality regulations, and mitigating issues related to stormwater runoff and flooding. The processes and tools used in watershed management planning are ever-evolving based on improved technologies, changing regulations, and social trends. In this study, 63 urban WMPs across the nation were reviewed to characterize historical approaches as well as identify emerging trends in watershed planning. Planning methods, tools of analysis, and recommended strategies were qualitatively evaluated to determine trends in the planning process, followed by statistical analyses to identify correlations between planning factors and methodologies. Plans developed by a municipality or consultant were correlated to higher occurrences of hydrologic modeling and site-specific recommendations, and lower occurrences of characterizing social watershed factors. Trends in the use and selection of hydrologic, hydraulic, and pollutant load models were identified, specifically in the past decade. Project prioritization was found to increasingly focus on feasibility in implementation. Other qualitative trends identified include an increased focus on water quality and interdisciplinary studies, public participation, responsiveness to water quality regulations, and risk aversion. The study concludes by envisioning future watershed planning trends. This state of the practice review of planning efforts, innovation in implementation, and the adoption of emergent technologies will aid future planners in employing current tools and strategies in the development of new WMPs. 


\section{ACKNOWLEDGEMENTS}

Many thanks go out to the Virginia Tech faculty and community for their support in completing this thesis. In particular, I want to thank Randy Dymond for serving as my committee chair, and for guiding me and for pushing me to give my best. I would also like to thank my committee members, Clay Hodges and Kevin Young, for their help and feedback.

Outside of my committee, I extend my sincerest gratitude to Marcus Aguilar for his significant contributions in not only his insight and help in completing this thesis, but also his mentorship and guidance. I would also like to thank the other members of my research group for their encouragement, support, and "coffee and gossip". Lastly, thank you to my friends and family for supporting me in my endeavors and for lending an ear when I need it most. 


\section{TABLE OF CONTENTS}

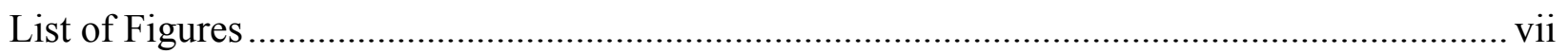

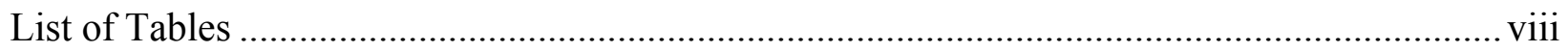

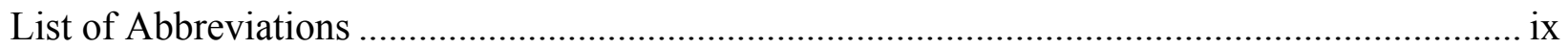

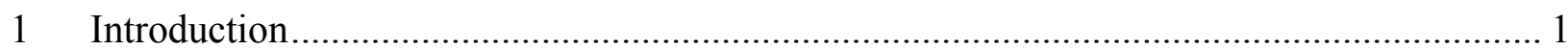

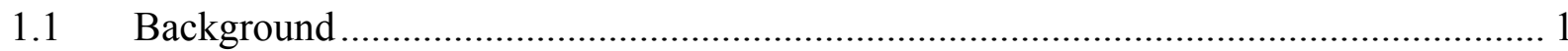

$1.2 \quad$ Problem Statement and Objectives …………………............................................... 2

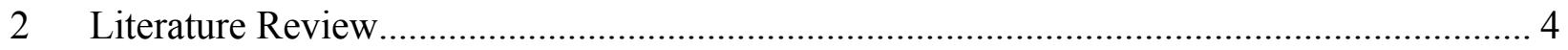

2.1 History of Watershed Management ……………….................................................... 4

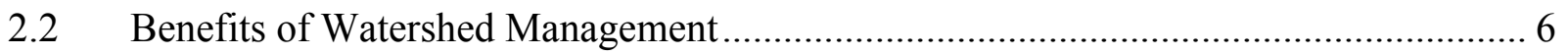

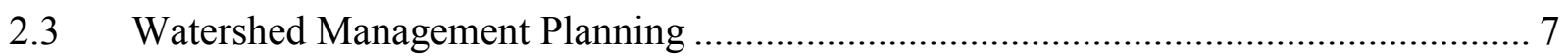

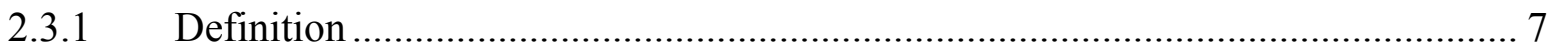

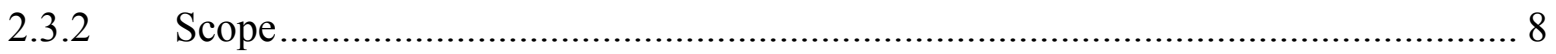

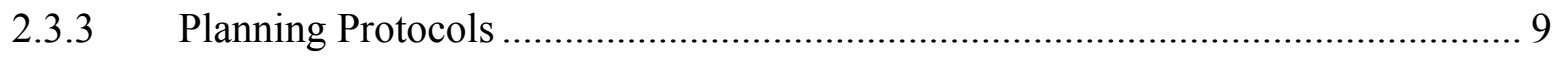

2.3.4 Shortcomings and Limitations .................................................................... 10

2.3.5 Adaptive Management ......................................................................................... 11

3 Evolution and Application of Urban Watershed Management Planning .............................. 13

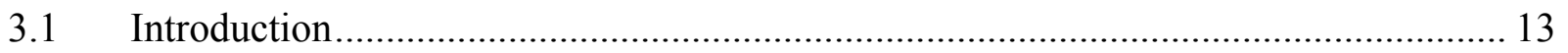

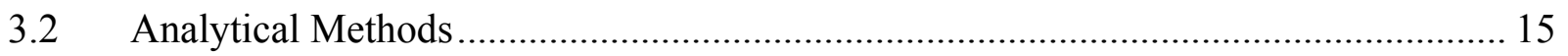

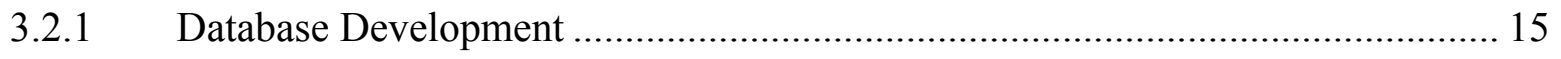

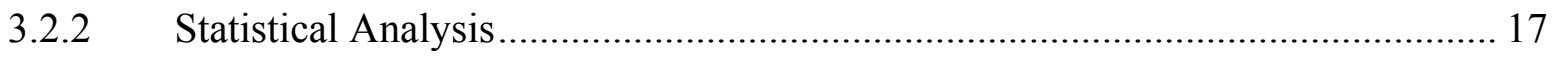

3.3 Summary of Statistical Results …………............................................................ 19

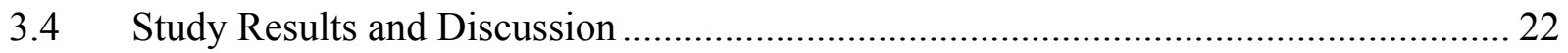

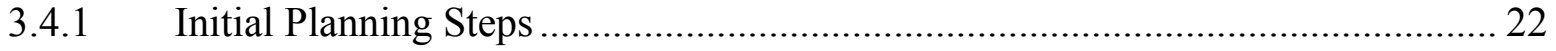




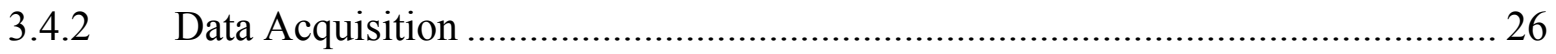

3.4.3 Tools for Watershed Assessment..................................................................... 28

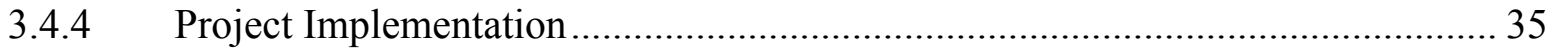

3.4.5 Emerging Trends in Watershed Management Planning ....................................... 37

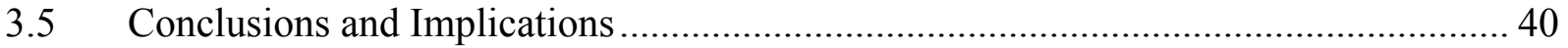

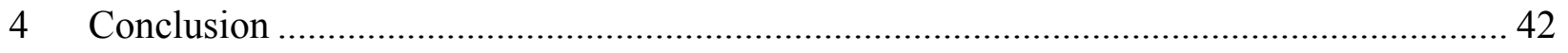

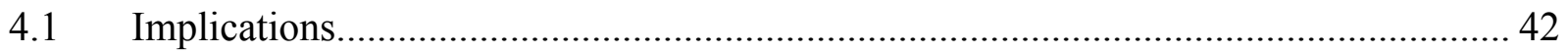

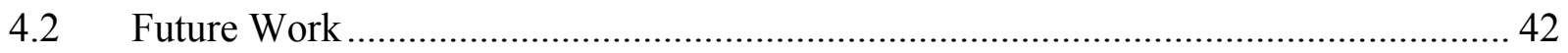

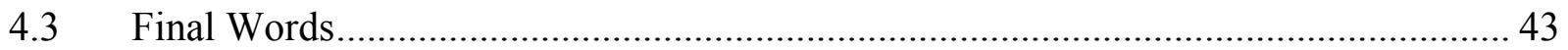

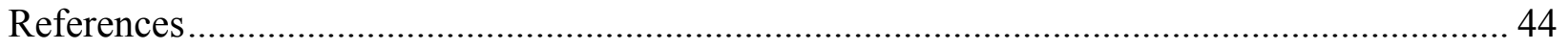

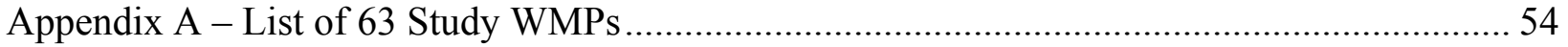

Appendix B - Template for Qualitative Review …………………………………................... 59

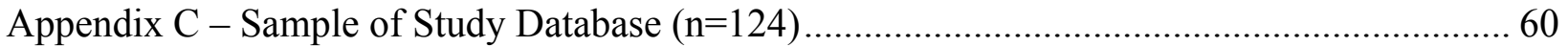




\section{LIST OF FIGURES}

Figure 3-1: Approximate geographic location of all watershed management plans (WMPs) collected. WMPs within the scope of the study $(n=124)$ are indicated by a darker shade.

Figure 3-2: Watershed size distribution for 124 urban WMPs. The final column, ">100", includes all WMPs with watershed study areas greater than $100 \mathrm{mi}^{2}$, up to a maximum of $250 \mathrm{mi}^{2}$

Figure 3-3: Frequency of WMP development plotted with the number of TMDLs issued nationwide, by year. Number of WMPs include all WMPs within the scope of the study ( $\mathrm{n}=124)$. Number of TMDLs does not refer to number of impaired water bodies; there may be multiple TMDLs issued for a single water body in a given year (EPA 2017b). 39 


\section{LIST OF TABLES}

Table 2-1: "Nine Key Elements" of watershed planning required by the EPA for plans funded by Section 319 Nonpoint Source Grants to States and Territories.

Table 3-1: Study factors for WMP analysis. Factors are categorized into Metadata, Watershed, and Planning Methodology. Data type describes the type of statistical variable, where "N/A" is for factors that were only qualitatively reviewed or not included in the statistical analysis. "Dichotomous" variables refer to "Yes" or "No" conditions.

Table 3-2: Results of statistical analysis for factors studied. Factor correlation was determined through contingency tables and Fisher's exact test. Statistically significant p-values are listed in ascending order.

Table 3-3: Positively correlated contingency table of stormwater infrastructure inventory, including BMPs, outfalls, and storm sewer system, against whether site-specific strategies were recommended (test T11). P-value $=0.0094$

Table 3-4: Negatively correlated contingency table of whether social factors were included in the watershed characterization against whether the plan was initiated by an MS4 municipality ("Yes") or initiated by an organization or agency ("No") (test T3). P-value $=0.0004 \ldots . . .21$

Table 3-5: "Nine Key Elements" of watershed planning required by the EPA for plans funded by Section 319 Nonpoint Source Grants to States and Territories (EPA 2008). Also referred to as the "a" through "i" criteria.

Table 3-6: Frequency and type of hydrologic/hydraulic models used in WMPs over time (in 5year periods). Note that some WMPs may utilize a combination of multiple models.

Table 3-7: Frequency and type of pollutant loading models used by WMPs over time (in 5-year periods). Model types are separated into calculation-based approximations, spreadsheetbased models, or GIS-based models. "Percent" indicates the percentage of WMPs that used a pollutant load model out of all WMPs. 


\section{LIST OF ABBREVIATIONS}

BEHI

Bank Erosion Hazard Index, 33, 34

BMPs

Best Management Practices, viii, 12, 21, $29,31,35,56$

CCTV

Closed-Circuit Television, 27

CSOs

Combined Sewer Overflows, 30

CWA

Clean Water Act, 6, 10, 26

CWP

Center for Watershed Protection, 9

DCIA

Directly Connected Impervious Area, 34

EIA

Effective Impervious Area, 34

EPA

U.S. Environmental Protection Agency, vii, viii, 1, 5, 6, 7, 9, 10, 11, 13, 14, 16, $18,19,20,23,25,26,27,31,33,39,40$

GIS

Geographic Information System, viii, 18, $24,26,27,28,31,32,33,34,41$
GPS

Global Positioning System, 27, 33

HEC

Hydrologic Engineering Center

(USACE), 29, 30, 40

HSPF

Hydrological Simulation Program Fortran, 30, 31

HUC

Hydrologic Unit Code, 8, 9, 23, 24

IC

Impervious Cover, 35

ICM

Impervious Cover Model, 34

IEPA

Illinois Environmental Protection Agency, $8,9,16,24$

ILLUDAS

Illinois Urban Drainage Simulator, 30

LiDAR

Light Detection and Ranging, 25

LSPC

Loading Simulation Program in $\mathrm{C}++, 29$, 32 
MS4

Municipal Separate Storm Sewer System, viii, 1, 2, 3, 14, 15, 18, 19, 20, 21, 22, $23,30,38,39$

NPDES

National Pollutant Discharge Elimination System, 30, 38

NRCS

Natural Resources Conservation Service,

$$
5,9
$$

PSRM

Penn State Runoff Model, 29, 30

RSAT

Rapid Stream Assessment Technique, 33

SCS

Soil Conservation Service, 13

\section{SLAMM}

Source Loading and Management Model, 31

STEPL

Spreadsheet Tool for Estimating Pollutant Loads, 32

SVAP

Stream Visual Assessment Protocol, 33

SWAT

Soil and Water Assessment Tool, 29, 32
SWMM

Storm Water Management Model, 29, 30, 32,40

TIA

Total Impervious Area, 34

TMDL

Total Maximum Daily Load, 14, 30, 35, 39

TVA

Tennessee Valley Authority, 5

USACE

U.S. Army Corps of Engineers, 29

USDA

U.S. Department of Agriculture, 11, 29, 33,53

USGS

U.S. Geological Survey, 8, 23

WAM

Watershed Analysis and Management, 10, 11

WIP

Watershed Implementation Plan, 6

WMP

Watershed Management Plan, vii, viii, 1, $2,8,9,10,11,13,15,18,22,23,25$, $28,29,35,37,39$ 


\section{INTRODUCTION}

\subsection{BACKGROUND}

Urban localities with a municipal separate storm sewer system (MS4), a stormwater conveyance system permit administered by the U.S. Environmental Protection Agency (EPA), are required to implement specific minimum control measures to reduce pollutants entering receiving water bodies to mitigate the effects of urbanization. One proactive approach to meeting these regulatory requirements and improving the hydrologic and ecologic functions of an urbanized watershed is through watershed management planning. Watershed management planning is defined by the EPA as a "strategy that provides assessment and management information for a geographically defined watershed, including the analyses, actions, participants, and resources related to developing and implementing the plan" (EPA 2008). It is a comprehensive planning mechanism to guide public policy by assessing the existing hydrologic and ecologic conditions of a watershed. The planning process culminates in the development of a watershed-based plan, henceforth referred to as a Watershed Management Plan (WMP), which encompasses an array of similar plans of differing terminologies, including but not limited to: Watershed Master Plan, Watershed Based Plan, Watershed Protection Plan, and Watershed Action Plan. The general procedure towards developing a WMP consists of establishing partnerships and setting plan goals; watershed characterization and analysis; implementation of recommended solutions; followed by evaluation, monitoring, and progress measurement (Davenport 2003; Doerfer and Urbonas 2004; EPA 2008). WMPs are a useful tool for municipalities because they can help prioritize areas within the watershed where improvement strategies could be implemented. Improvement strategies may be in the form of grey infrastructure, such as culvert or pipe improvements, green infrastructure, such as detention ponds and stream restorations, or other non-structural management strategies such as public outreach and education.

Watershed-based management is a concept that was first proposed in 1878 by John Wesley Powell, and it has been used in practice since the early 1900's (Gregg et al. 1998). Watershedbased management was historically a top-down approach, and has since evolved into a more bottom-up process that values local participation (Western Water Policy Review Advisory Commission 1998). The 1990's are known as the decade in which the watershed approach 
became widely popularized as a method of environmental management (Schueler 1996). Although the watershed-based approach has become popularized, there is little agreement among policy makers over methodology to develop and implement watershed-based plans (McGinnis 1999), and methodologies for an integrated watershed approach have been changing in response to rapidly developing technologies (Wang et al. 2016). It is important to understand the evolution of watershed management planning in order to better inform future efforts, as the processes and tools used in watershed planning are ever-evolving based on improved technologies, changing regulations, and social trends.

\subsection{Problem Statement and ObJectives}

The watershed management planning process is not well documented within the scientific community. Understanding historical methodology and identifying trends in watershed management processes is important as good planning processes can lead to better recommendations and implementation by decision makers (Born and Genskow 2001). There are numerous state- or regional-level documents and manuals that suggest methods for developing WMPs, however, many documents are outdated. The methods for developing WMPs are varied and may even be inconsistent within a municipality if watersheds are handled by different consulting companies. For example, in Lincoln, NE between 2000 and 2015, ten WMPs were developed by five different engineering consulting companies (City of Lincoln n.d.). Additionally, the methods are continuously changing and developing based on new knowledge, advanced technologies, and the availability of more precise data.

The purpose of this study is to investigate the evolution of watershed management planning in urban areas based on historic and current methodologies, and to provide guidance to urban municipalities with an MS4 to effectively develop, understand, and implement a Watershed Management Plan (WMP). The objectives for this study are as follows:

1. Review existing literature on watershed management planning guidance manuals, methodologies, and planning documents

2. Evaluate and compare the historical methodologies of watershed planning

3. Investigate the current methodologies that are available tools for watershed planning 
4. Provide guidance to urban municipalities on the future of watershed management planning

Although the focus of the study will be on urban municipalities with an MS4, this review of watershed master planning methodologies will also be applicable to non-permitted urban localities. WMPs can help mitigate the effects of urbanization on watershed health and function beyond meeting regulatory requirements, and may also proactively prevent water body degradation before regulatory agencies get involved, such as impairment listings or Total Maximum Daily Loads (TMDLs). Therefore, any urban locality could benefit from effective watershed management strategies.

The scope of this study is WMPs developed by or for urban municipalities with an MS4 permit, and watershed study areas of approximately $50 \mathrm{mi}^{2}$ or less. Watershed study areas larger than this tend to focus on basin scale management with low-resolution analysis. Additionally, management at the basin scale typically does not consider stormwater infrastructure or recommend site-specific strategies. This study will focus on urban municipalities as these entities have the authority to implement improvement strategies, are driven by regulations, and could benefit from effective watershed planning. 


\section{Literature REVIEW}

Land-use changes, specifically urbanization, can have significant effects on local hydrologic functions. The effects of urbanization on the hydrology of a landscape include changes in peak flow characteristics, the volume of runoff, water quality, and the appearance of water bodies due to increased impervious surfaces (Leopold 1968). Stream degradation has been shown to begin to appear at 10\% imperviousness, with 30\% imperviousness causing severe degradation (Arnold and Gibbons 1996). This modified hydrology from urban areas can degrade streams, rivers, and other water bodies in the form of impaired water quality from stressors such as sediment or contaminants, as well as incised or eroded banks from increased peak flows (Walsh et al. 2005).

One approach to addressing water quantity and quality issues related to land-use changes is management at the watershed scale. Watersheds are appropriate units of analysis as their boundaries are typically well defined by topographic drainage divides and their processes are well researched (Arnold 2010; Ruhl 1999). Watersheds are also meaningful from an ecological perspective; often the health of the watershed as a whole can be determined based on the health of the aquatic system (McGinnis 1999). The watershed boundary provides a meaningful management extent for organizations and municipalities. Issues that are within clear management boundaries are more likely to be carefully addressed than problems that lie outside of the scope of management (Blomquist and Schlager 2005). The history of watershed management in the U.S., the benefits of management and planning efforts at the watershed scale, and a review of watershed management planning is discussed in the following sections.

\subsection{History OF WATERSHED MANAGEMENT}

John Wesley Powell first proposed the concept of watershed-based planning to Congress in 1878 with a vision of pioneering the West that would delineate political boundaries coincident to watershed divides. This arrangement would have greatly altered the design of the region as it is now, and in part would have limited the growth potential if not altogether prevented the existence of populous water-stressed cities such as Los Angeles and Phoenix (McGinnis 1999). The interest in watershed management has since waxed and waned over the years (Heaney et al. 2000). Many prior watershed and basin management attempts were conducted as "top-down" 
federal efforts that ultimately imposed on jurisdictions a form of coordinated management (Western Water Policy Review Advisory Commission 1998), although conflicting objectives of the federal agencies resulted in gridlock rather than coordination. Watershed management practices have since evolved into more "bottom-up" approaches that emphasize local partnerships.

The U.S. Inland Waterways Commission reported to Congress in 1908 that river systems should be treated as an integrated system, one of the first examples of water resources management within watersheds (EPA 1995). Other early efforts driven by federal agencies were largely conceived during the progressive conservation era in the early 1900's. The extensive private control of resources that resulted in widespread deforestation prompted conservationists to transfer control of natural resources to federal agencies (Gregg et al. 1998). Watershed management was one practice that also spawned from the progressive era. The Tennessee Valley Authority (TVA) undertook an experimental and ambitious regional water management project in 1933 that initiated an era coined the "renaissance of regionalism" (Gregg et al. 1998).

Although the attention given to watershed management during this time was largely focused on regional projects, the Soil Conservation Service (now known as the Natural Resources Conservation Service, NRCS) established a "small watersheds program" in 1954 to fund local organizations and state governments to address erosion and flooding problems at a smaller scale (Gregg et al. 1998). This program provided a model for more localized watershed management that further fueled the shift towards "bottom-up" management. Other federal interagency river basin committees formed during this time did not prove as effective in improving coordinated efforts (Gregg et al. 1998).

A notable change that rose out of the end of the $20^{\text {th }}$ century was the diffusion of legal authority to a larger set of partnerships with shared responsibility, encouraging "bottom-up" approaches over previous "top-down" federal efforts (Committee on Watershed Management 1999; Western Water Policy Review Advisory Commission 1998). Many states added provisions of "public interest" and "public welfare" into state water codes as the state role in water management became more prominent (Gregg et al. 1998). Although the state and local role was ever 
increasing, the federal role did not disappear. By the end of 1999, there were 17 federal agencies that had adopted watershed-based approaches (McGinnis 1999).

After the adoption of the Clean Water Act (CWA), the increasing challenge of addressing nonpoint source pollution encouraged agency cooperation. Section 319 of the CWA offered a powerful source of federal grants to watershed initiatives seeking to address local water quality issues associated with nonpoint source pollution. This program, also known as the Section 319 Nonpoint Source Management Program, quadrupled the amount of grant funding between 1990 and 2000 (EPA 2017a). The 1990's are known as the decade in which the watershed approach became widely popularized as a method of environmental management (Schueler 1996).

The modern watershed movement continues to focus more on practical solutions to watershed problems in addition to exclusively addressing distinct legal issues (Gregg et al. 1998). This has the potential to overcome the limitations of past management approaches of conflicting federal agencies. Watershed management has since continued to dynamically evolve to adapt to modern technologies, a better understanding of hydrologic processes, and changing management goals (Davenport 2003).

\subsection{Benefits of Watershed Management}

Federal, state, local, and nongovernmental organizations' planning efforts are commonly limited to traditional site-specific strategies, which may not protect water quality at the watershed scale (Brabec 2009). It is therefore reasonable for jurisdictions and organizations to undertake management efforts that focus on watersheds as the unit of analysis. It has long been suggested that existing jurisdictions combine and transfer resources to form an integrated watershed-scale management program (Blomquist and Schlager 2005).

Traditional management of water resources may also focus on specific aspects of water management, such as drinking water quality, flood prevention and mitigation, habitat restoration, or wetland preservation. For example, Watershed Implementation Plans (WIPs) may be tailored to address certain regulations, such as water quality improvements in response to Total Maximum Daily Loads (TMDLs), but may not guide policy for all aspects of the watershed. 
Watershed approaches can enhance program efficiency, coordination among agencies, and the distribution of resources and funding (Browner 1996; EPA 1995).

\subsection{Watershed Management PlanNing}

\subsubsection{Definition}

One form of watershed management is a process called watershed management planning. Watershed management planning is defined by the EPA as a "strategy that provides assessment and management information for a geographically defined watershed, including the analyses, actions, participants, and resources related to developing and implementing the plan" (EPA 2008). It is a systematic procedure to locate problems within the watershed and to identify alternative solutions, following the general steps of assessment, planning, and implementation, followed by evaluation (Davenport 2003). Watershed Management Planning is a science-based and community-driven approach to address long-term management of watershed impairment requiring diverse participation based on skills and knowledge (EPA 2008).

There is a distinction between a watershed "study" and a watershed "plan". While a watershed study is technical analysis used to identify problems, a watershed plan is a more comprehensive process that leads to implementation and assessment of successes and failures (Schueler 1996). Plans need to focus on achieving specific and obtainable goals, although these are more often reactive to addressing existing problems rather than proactive towards preventing future degradation (Davenport 2003). While watershed planning and management was historically applied to solve flood related problems, current plans attempt to integrate principles of flood control, fluvial geomorphology, and water quality (Doerfer and Urbonas 2004), as well as habitat, ecology, and community values (EPA 2013). A critical aspect of watershed-based management is balancing the needs of society with the needs of the environment. The watershed approach recognizes the complex interactions between humans and the ecosystem; it is said that "managing for one without considering the other can be detrimental for both" (EPA 1995).

Watershed management planning is also an important tool for municipalities to inform and engage the public and stakeholders. Stakeholders should have access to scientific information regarding physical watershed processes in order to create a sense of "ownership" and allow them 
to be effectively involved in management decisions (Maguire 2003). The WMP creates a venue of communication between stakeholders and the scientists assessing and modeling the watershed. The involvement and sense of "ownership" by stakeholders and the public is not only important for informing policy decisions, but also because watersheds are as much a cultural construct as a scientific unit of analysis due to the associations, relationships, and partnerships that might develop on a watershed basis (McGinnis et al. 1999). The watershed is composed of communities of people that interact with and impact the natural and built landscape, and these cultural conditions have the potential to influence watershed planning practices. For example, the level of involvement of the community with regard to the watershed can greatly influence the success of particular restoration efforts or management approaches (Shilling et al. 2005). For this reason, watershed planning should include an understanding of the history, politics, economics, and culture of the watershed (Allan et al. 2008). It also is critical that local municipalities, stakeholders, and the public be actively involved in the watershed planning process.

\subsubsection{Scope}

One of the primary causes of unsuccessful plan implementation is that the plan is conducted at too large or small a scale (Davenport 2003; Schueler 1996). Planning efforts conducted in smaller watersheds may discourage integration and neglect broader watershed context (Blomquist and Schlager 2005). At broader scopes, however, localized problems and detailed analyses are sacrificed for a larger area of coverage. The selection of an appropriate geographic scale for the watershed study largely depends on the desired level of detail. The USGS uses a hierarchical Hydrologic Unit Code (HUC) to describe the location and relative size of a watershed, which ranges from HUC-2 at the regional level to HUC-12 at the subwatershed level. Larger basin or subbasin studies (HUC-6 and HUC-8) are more realistic in rural watersheds of homogeneous land use with few pollutants of concern, such as sediment from agricultural practices (Davenport 2003; IEPA 2007) Watershed studies focusing on a smaller area (HUC-10 and HUC-12) are able to accommodate a higher level of detail in analysis, such as urban stormwater infrastructure and multiple water quality constituents (EPA 2008).

The Center for Watershed Protection (CWP) defines "small urban watersheds" as between 20 and $100 \mathrm{mi}^{2}$ (Schueler 1996). This allows for easier incorporation with stakeholders and fewer 
political jurisdictions. While it is recognized that planning may need to occur up to the $100 \mathrm{mi}^{2}$ watershed scale, watersheds below $50 \mathrm{mi}^{2}$ are the recommended management planning units (Schueler 1996). The Illinois Environmental Protection Agency (IEPA) suggests that watershed projects be limited to $63 \mathrm{mi}^{2}$ or less, with $50 \mathrm{mi}^{2}$ as the recommended maximum for urban projects (IEPA 2007). Other studies have cited $50 \mathrm{mi}^{2}$ as the recommended maximum watershed study area because it encourages more local involvement, can provide more site-specific recommendations, and has fewer players sharing the responsibility to implement (DeShazo et al. 1996).

\subsubsection{Planning Protocols}

Many municipalities have developed WMPs that have taken various forms. For example, Fairfax County, VA has developed 13 WMPs between 2005 and 2011 for their 30 watersheds (Fairfax County 2015). Other examples of WMPs have been developed by Atlanta, GA (City of Atlanta 2017); Lake County, IL (Lake County 2017); and Durham, NC (Durham 2017). These WMPs help to guide policy and prioritize implementation of restoration and improvement projects in the watershed. The task of developing a WMP may be given to a consultant or other external entity, or it may be produced by the local government itself.

To facilitate the creation of a WMP, multiple documents, or watershed planning manuals, have been developed at the state or regional level. Watershed planning protocols have been developed by agencies such as the Environmental Protection Agency (EPA), Bureau of Reclamation, and the National Resource Conservation Service (NRCS) (Committee on Watershed Management 1999). The EPA specifically has developed a set of watershed planning guidelines for states and communities based on a "watershed approach". This watershed approach focuses on targeting priority problems in the watershed, involving stakeholders, using integrated solutions from interdisciplinary agencies, and measuring success through monitoring (EPA 1995). The EPA describes the benefits of using a watershed approach as providing a "unique and effective way to assess the environment, identify problems, establish priorities for preservation or restoration, and implement solutions" (EPA 2003). A comprehensive methodology, called Watershed Analysis and Management (WAM), was first developed by the EPA in 1997 (EPA 2003). More recently, the EPA has identified the "Nine Key Elements" that are critical for developing an effective 
watershed plan to address nonpoint source pollution (EPA 2008). These nine elements must be addressed in watershed plans that are funded by the CWA 319(h) program, listed in Table 2-1. This EPA method focuses on nonpoint source pollutant load reduction in order to meet water quality standards.

Table 2-1: "Nine Key Elements" of watershed planning required by the EPA for plans funded by Section 319 Nonpoint Source Grants to States and Territories.

\begin{tabular}{ll}
\hline a. & Identify causes and sources of pollution \\
b. & Estimate load reductions expected \\
c. & Describe management measures and targeted critical areas \\
d. & Estimate technical and financial assistance needed \\
e. Develop an information and education component \\
f. Develop a project schedule \\
g. Describe interim, measureable milestones \\
h. Identify indicators to measure progress \\
i. Develop a monitoring component
\end{tabular}

Similar agencies, state governments, or smaller organizations have followed suit in developing manuals for watershed assessment and management to facilitate the creation of a WMP at the state or regional level. For example, the "User's Guide to Watershed Planning in Maryland" (Center for Watershed Protection 2005) or the "California Watershed Assessment Manual" (Shilling et al. 2005). The EPA "Handbook for Developing Watershed Plans to Restore and Protect Our Waters", developed in 2008, is frequently referenced by watershed planners or watershed planning guidance manuals, and provides a detailed, step-by-step procedure for developing WMPs (EPA 2008).

\subsubsection{Shortcomings and Limitations}

Early watershed management attempts, such as the U.S. Department of Agriculture (USDA) Small Watershed Program in 1954, were often not fully successful because project focuses were too narrow, there were too few regulations to provide measurable goals, and there was a lack of available technology for data acquisition (Davenport 2003). More current Watershed Management Planning efforts have similarly found that the factors that led to no implementation 
of the plans included a lack of funding, enforcement, awareness, and cooperation (Koski and Lorenz 1999). An important factor leading to the success of a WMP is whether the plan has any regulatory meaning, or mechanisms for enforcement. Although a lack of funding can lead to unsuccessful implementation of plans, some watershed initiatives have found that federal support may come at the expense of restrictions on their planning processes (Gregg et al. 1998). Restricted planning may hinder the success of the plan and discourage innovation or implementation.

Many of the recommended planning procedures, such as the EPA WAM approach, are focused on a scientific process for assessing watersheds, however they may not provide guidance on how the planning steps are applied (Committee on Watershed Management 1999). Other shortcomings that are common to watershed assessments are the cataloging of data with little analysis, scarce integration of different aspects of assessment, or weak application of the science to decision-making processes (Shilling et al. 2005).

The watershed planning process is one that is continually being revised and refined. Although certain aspects of watershed management have been shown to be more successful than others, there is no single catch-all process that can encompass the diverse needs of each individual watershed. Each watershed's unique characteristics, circumstances, and management approaches need to be addressed using a flexible process that takes advantage of emerging opportunities (Davenport 2003).

\subsubsection{Adaptive Management}

Watershed management continues to grow in use and feasibility as more advanced technologies and technical tools become available (Committee on Watershed Management 1999). An effective way to improve upon the watershed management strategies is through a concept called adaptive management. Adaptive management consists of a continuous and iterative feedback loop of implementation followed by assessment and improvement, where failures and shortcomings are embraced so that it provides an opportunity to learn and change (Allan et al. 2008). This process can allow for management to progress and improve under uncertain and variable conditions (Jensen et al. 1996). This is particularly applicable for watershed management as stormwater regulatory programs may not adequately account for the many 
limitations to the technical knowledge available, such as the effectiveness of BMPs (Brabec 2009; Wagner 2006). Others have suggested that watershed planning could be the leader in forging the future of climate change modeling (Arnold 2010). Watershed planning creates a demand for more accurate climate change models that can help to improve flood frequency analyses. It is therefore imperative that the process of watershed master planning be adaptive to improved methodologies based on historic successes and failures.

Current watershed planning has been often shown to possess "risk aversion" that may not adequately promote adaptive management (Arnold 2010). One possible cause for risk aversion in watershed planning is that there are few incentives for risk-taking and innovation (Allan et al. 2008). One community-based watershed group in Oregon expressed that their willingness to explore alternative solutions was deterred when they were singled out for praise and, under the spotlight, were dissuaded from taking more innovative or risky approaches (Gregg et al. 1998). Another factor that might contribute to risk aversion is strict adherence to watershed planning guidance manuals and standard procedures. The Center for Watershed Protection states that, "Much of the watershed planning field is so new that each plan is basically its own watershed experiment" (Center for Watershed Protection 2005). Innovation and experimentation in watershed planning can improve future efforts by exploring new options and by assessing successes and failures. 


\section{EVOLUTION AND APPLICATION OF URBAN WATERSHED Management Planning}

\subsection{INTRODUCTION}

John Wesley Powell first proposed the concept of watershed-based planning to Congress in 1878 with a vision of drawing political boundaries coincident to watershed divides. Although Powell's proposal was rejected at the time, the concept of management at the watershed-scale has since become widely popularized. Early watershed endeavors were conducted as "top-down" federal efforts that ultimately imposed a form of coordinated management on jurisdictions (Western Water Policy Review Advisory Commission 1998). The inherent conflicting objectives of federal agencies resulted in gridlock rather than coordination, which other programs attempted to overcome through narrower foci. For example, the Small Watersheds Program was established in 1954 by the Soil Conservation Service (SCS) to address local erosion and flooding problems at a smaller scale (Gregg et al. 1998). Programs such as these provided a model for more localized watershed management that further fueled a shift at the end of the $20^{\text {th }}$ century towards "bottomup" management (Committee on Watershed Management 1999). This approach involved the diffusion of legal authority to a larger set of partnerships with shared responsibility. The modern watershed movement continues to focus more on practical solutions to watershed problems rather than becoming stymied by legal rights and jurisdictional delineations (Gregg et al. 1998). Watershed management has since been dynamically evolving to adapt to modern technologies, a better understanding of hydrologic processes, and changing management goals (Davenport 2003).

One manifestation of watershed-based management is watershed management planning: a science-based and community-driven approach to address long-term management of watershed impairment (EPA 2008). It is a systematic procedure to locate problems within the watershed and to identify alternative solutions. The planning process culminates in the development of a watershed-based plan, henceforth referred to as a Watershed Management Plan (WMP), which encompasses an array of similar plans of differing terminologies, including but not limited to: Watershed Master Plan, Watershed Based Plan, Watershed Protection Plan, and Watershed Action Plan. The general procedure towards developing a WMP consists of establishing 
partnerships and setting plan goals; watershed characterization and analysis; implementation of recommended solutions; followed by evaluation, monitoring, and progress measurement (Davenport 2003; Doerfer and Urbonas 2004; EPA 2008). Evaluation and progress measurement are a form of adaptive management, a continuous and iterative feedback loop of implementation followed by assessment, where failures and shortcomings are embraced to provide an opportunity to improve (Allan et al. 2008; NRC 2004). This process can allow for management to progress and improve under uncertain and variable conditions (Jensen et al. 1996). Plan evaluation enables planners to identify areas of improvement so that previous steps of the planning process can be revisited and adapted to improve methodologies based on historic successes and failures.

Watershed management planning can also be a useful prioritization tool for urban localities required to implement structural and non-structural stormwater controls, pursuant to requirements of municipal separate storm sewer system (MS4) permits and total maximum daily load (TMDL) waste load allocations (33 USC 26, $\S 402$ and 303, respectively). Planning for implementation of controls in urban areas is especially challenging because multiple objectives (e.g. flood control, erosion and sediment control, aquatic insect impairments) must be fulfilled with limited available space for implementation, relatively high cost of land, complex surface and subsurface drainage patterns, and constraints of local government budgets (Lee et al. 2012; McGarity 2012; Walsh et al. 2016). A watershed-based approach can benefit municipal planning efforts as these approaches can enhance program efficiency, improve coordination among agencies, and better allocate the distribution of resources and funding (Browner 1996). WMPs can equip planners to prioritize implementation projects that address local concerns related to public health and safety, flooding, water quality regulations, and watershed aesthetics.

Additional benefits of watershed planning for urban municipalities include providing a venue of communication between governing bodies, stakeholders, and the public. Watersheds are composed of communities of people that interact with and impact the natural and built landscape. The level of involvement of the community with regard to the watershed can greatly influence the success of particular restoration efforts or management approaches (Shilling et al. 2005). Additionally, watershed plans allow policy makers and stakeholders to have access to scientific information regarding physical watershed processes to allow them to be effectively involved in 
management decisions (Maguire 2003). This sharing of information is particularly essential when policy makers are required to make technically complex environmental policy decisions (Chess and Purcell 1999).

Although the watershed management approach has earned prevalence, there is little agreement among policy makers over methodology to develop and implement watershed-based plans (McGinnis 1999), and methodologies for an integrated watershed approach have been changing in response to rapidly developing technologies (Wang et al. 2016). This study aims to investigate the evolution of watershed management planning in urban areas based on historic and current methodologies, and to provide guidance to urban municipalities with an MS4 to effectively develop, understand, and implement a WMP. To achieve this goal, 63 WMPs were evaluated for several factors related to general methodology or unique planning procedures, with a focus on small urban watersheds. These factors were then used to identify trends in the watershed planning processes through qualitative review and statistical analysis. The intent of this study is to provide a state of the practice review of watershed management and to identify emerging trends in planning methodology as evidenced by existing plans and published literature, rather than to gauge the success of the plans or rank the plan effectiveness. It is important to understand the evolution of watershed management planning in order to better inform future efforts, as the processes and tools utilized continue to evolve with improved technologies, changing regulations, and social trends. The results of the study are first presented as a statistical summary of the WMP documents reviewed, followed by a state of the practice review and discussion of observed trends.

\subsection{Analytical Methods}

\subsubsection{Database Development}

Numerous spatially and temporally diverse urban WMPs were reviewed to compare and assess trends in planning methodologies. Urban watersheds are the focus of this study as urbanization significantly affects local hydrologic functions and contributes a number of stressors on water body health, including increased rate and volume of stormwater runoff and water quality degradation (Leopold 1968; Walsh et al. 2005). Furthermore, the study focuses on urban municipalities as these jurisdictions have the authority to implement improvement strategies, are 
driven by regulations, and can benefit from effective watershed planning. In addition to a review of WMPs, various watershed management planning guidance manuals and protocols sourced from state agencies or organizations were collected for qualitative analysis. These documents provide insight into planning methodologies and trends, and were further supported by a review of current and historic watershed management literature.

The scope of this study was limited to urban watersheds of approximately $50 \mathrm{mi}^{2}\left(130 \mathrm{~km}^{2}\right)$ or less, as this threshold has been identified in the literature as the preferred maximum watershed study area size (EPA 2008; IEPA 2007). Watershed study areas larger than this threshold tend to focus on basin-scale management with low-resolution analysis (Schueler 1996), and management solutions at this scale may not consider stormwater infrastructure or recommend site-specific strategies. Some exceptions to the $50 \mathrm{mi}^{2}$ limit were made if the plan was developed by or for an urban municipality, which may be the case in expansive metropolitan areas such as Los Angeles, CA or Austin, TX, or if the plan encompassed multiple watersheds.

A database of over 250 WMPs, shown in Figure 3-1, was developed for nationwide plans written between 1976 and 2017, with the majority of plans written after the year 2000. The database was restricted to plans that were available online through organization or municipality web pages. This limits the study to digitally available plans, which may not capture older plans written prior to the 1990's, as these may not have been converted to digital format or made available for public use. Plan metadata including plan name, location, year, watershed size, and land use were collected. This metadata was used to identify 124 urban WMPs that fall within the scope of the study. To ensure statistical independence, this set of WMPs was further reduced to 63 plans to remove duplication in locations where multiple plans were developed by the same municipality or organization using similar planning methodologies. 


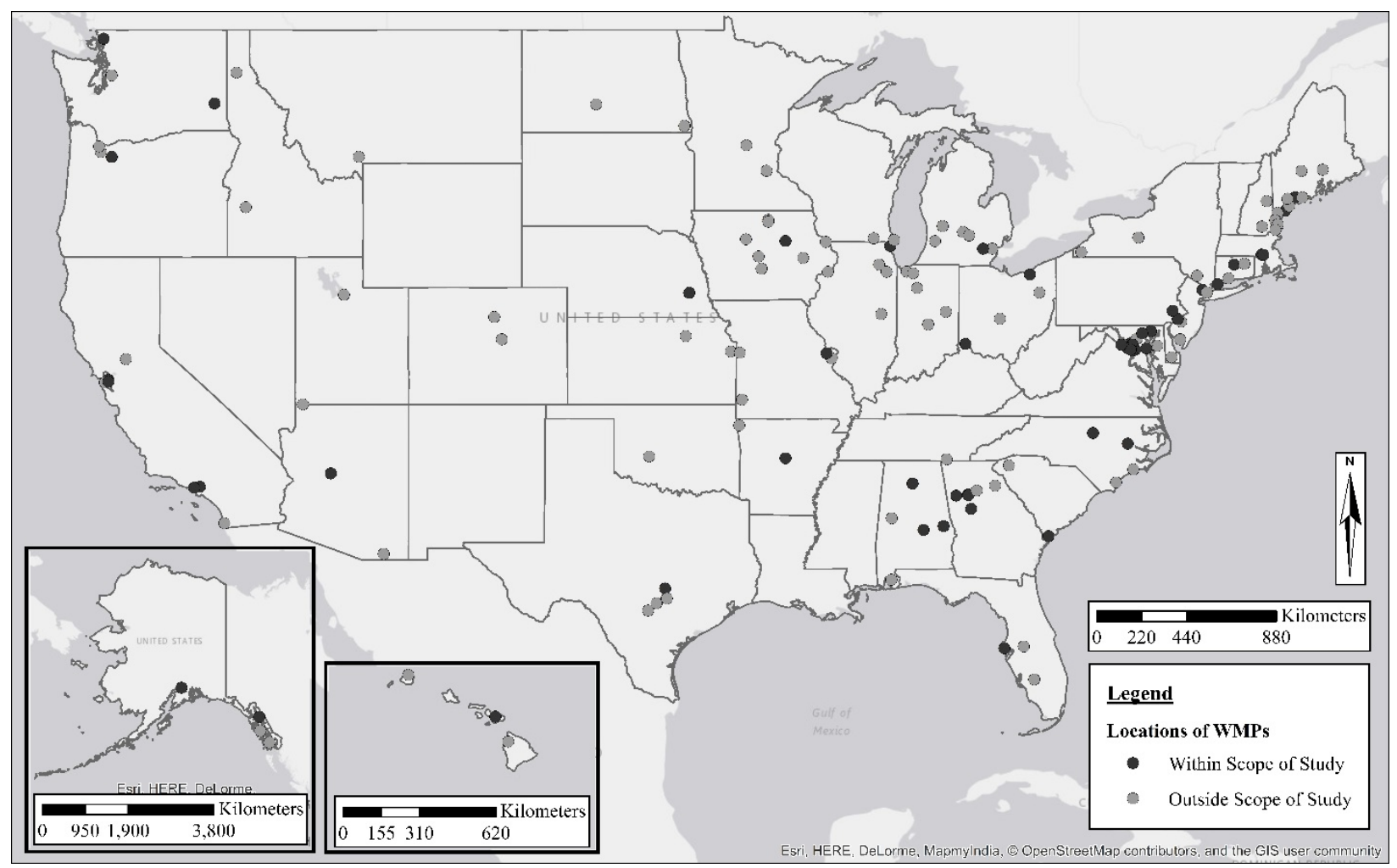

Figure 3-1: Approximate geographic location of all watershed management plans (WMPs) collected. WMPs within the scope of the study $(n=124)$ are indicated by a darker shade.

\subsubsection{Statistical Analysis}

After identification of the 63 WMPs for study inclusion, the plans were comprehensively reviewed to characterize the planning methodologies utilized. During the first stage, each plan was qualitatively assessed for various factors as listed in Table 3-1. In the second stage, qualitative factor information was transformed into continuous or categorical variables, as appropriate, for further data analysis. Variables included in the statistical analysis are noted with a number and data type in Table 3-1. 
Table 3-1: Study factors for WMP analysis. Factors are categorized into Metadata, Watershed, and Planning Methodology. Data type describes the type of statistical variable, where "N/A" is for factors that were only qualitatively reviewed or not included in the statistical analysis. "Dichotomous" variables refer to "Yes" or "No" conditions.

\begin{tabular}{|c|c|c|c|}
\hline Factor Type & Number & Data Type & Factor \\
\hline \multirow{6}{*}{ Metadata } & & N/A & Unique WMP ID \\
\hline & & $\mathrm{N} / \mathrm{A}$ & Location \\
\hline & 01 & Continuous & Year \\
\hline & 02 & Nominal & $\begin{array}{l}\text { Author type (consultant, organization, agency, or } \\
\text { university) }\end{array}$ \\
\hline & 03 & Dichotomous & Author type as consultant (YES $=$ consultant, $\mathrm{NO}=$ other $)$ \\
\hline & & N/A & Watershed plan name \\
\hline \multirow{4}{*}{ Watershed } & 04 & Continuous & Watershed size \\
\hline & 05 & Continuous & Land use (percent impervious or developed) \\
\hline & 06 & Dichotomous & Plan initiated by a municipality (MS4) \\
\hline & 07 & Dichotomous & Impairments, 303(d) \\
\hline \multirow{18}{*}{$\begin{array}{l}\text { Planning } \\
\text { Methodology }\end{array}$} & 08 & Dichotomous & Plan focused on water quality \\
\hline & 09 & Dichotomous & Plan focused on water quantity \\
\hline & & N/A & Public/stakeholder involvement \\
\hline & 10 & Dichotomous & EPA "Nine Key Elements" method followed \\
\hline & & $\mathrm{N} / \mathrm{A}$ & Type of physical features characterized \\
\hline & 11 & Dichotomous & Social features characterized \\
\hline & 12 & Dichotomous & Stormwater infrastructure inventoried \\
\hline & & N/A & Water quality assessment methods and models \\
\hline & 13 & Dichotomous & Water quality modeling performed \\
\hline & & $\mathrm{N} / \mathrm{A}$ & Water quantity assessment methods and models \\
\hline & 14 & Dichotomous & Water quantity modeling performed \\
\hline & 15 & Nominal & $\begin{array}{l}\text { Type of water quality model (calculation, spreadsheet, } \\
\text { or GIS-based) }\end{array}$ \\
\hline & & N/A & Stream condition survey methods \\
\hline & 17 & Dichotomous & Stream condition survey performed \\
\hline & & N/A & Recommended improvement strategies \\
\hline & 18 & Dichotomous & Education and outreach recommended \\
\hline & 19 & Dichotomous & Site-specific strategies recommended \\
\hline & & $\mathrm{N} / \mathrm{A}$ & Implementation timeline/budget \\
\hline
\end{tabular}

Factors to be included in the statistical analysis were categorized into continuous or discrete variables. Continuous variables included numerical factors such as year and watershed size. Discrete or categorical variables included nominal factors (e.g. author type) and dichotomous factors (e.g. stream impairment, Y/N). Dichotomous factors describe the presence or absence of said method, also known as a "Yes" or "No" condition. 
Statistical analyses were performed using R 3.4.2 (R Core Team 2017). Categorical variables were analyzed using contingency tables and tested for statistical significance using Fisher's exact test (Fisher 1970). Fisher's exact test determines whether there is a nonrandom association between two categorical variables. A two-tailed $95 \%$ confidence interval was considered statistically significant $(\mathrm{p} \leq 0.05)$. At $\mathrm{p} \leq 0.05$, it can be reasonably concluded that there is a statistically significant relationship between the two tested factors. Fisher's exact test was selected over similar analyses such as the chi-squared approximation as this test is appropriate for smaller sample sizes, such as in this study, with occurrences of low frequencies (less than 5) in a given cell in the contingency table.

It was postulated that WMPs initiated by MS4 municipalities or written by a consultant would produce plans that used more advanced modeling tools and were more focused on recommending site-specific strategies, while WMPs initiated or written by organizations or agencies would be more focused on the community aspect and have a reduced access to modeling tools. It was additionally hypothesized that the presence of Clean Water Act Section 303(d) waterway impairments or the use of Section 319(h) funding (and consequently the EPA "Nine Key Elements" planning approach) would influence planning methodologies. Other factors such as the collection of infrastructure data or the use of hydrologic, hydraulic, and pollutant load models were hypothesized to correlate with the prevalence of site-specific recommendations. Additional qualitative trends in planning methodologies were postulated, including the progressive emergence of public participation, water quality and ecological considerations, and the use of modeling software.

\subsection{Summary of Statistical Results}

Statistical analyses were performed on factors generated from a set of WMPs to identify trends in management procedures or correlations between planning factors, and serve to support the state of the practice review. These trends and correlations indicate potential areas of further study to understand the complex relationships between planning methodologies. Relationships between the variables described in Table 3-1 were tested for statistical significance, where $p \leq 0.05$, using Fisher's exact test. The results of statistically significant correlations are summarized in Table 32 by ascending $\mathrm{p}$-value. The statistical results presented herein are further described in the study 
results and discussion section, and will be referred to by the corresponding Test Number (e.g. $\mathrm{T} 1, \mathrm{~T} 2$, etc.).

Table 3-2: Results of statistical analysis for factors studied. Factor correlation was determined through contingency tables and Fisher's exact test. Statistically significant p-values are listed in ascending order.

\begin{tabular}{lllll}
\hline Test & & Factor B & P-value & Correlation \\
Number & Factor A & Quantity Model (14) & $5.6 \mathrm{E}-05$ & POSITIVE \\
T1 & Quantity (09) & 0.0001 & POSITIVE \\
T2 & Infrastructure Inventory (12) & Quantity Model (14) & 0.0004 & NEGATIVE \\
T3 & MS4 (06) & Social Factors (11) & 0.0012 & NEGATIVE \\
T4 & Quantity (09) & Quality Model (13) & 0.0019 & NEGATIVE \\
T5 & Social Factors (11) & Quantity Model (14) & 0.0022 & POSITIVE \\
T6 & Quality (08) & Quality Model (13) & 0.0027 & POSITIVE \\
T7 & Author as Consultant (03) & Infrastructure Inventory (12) & 0.0033 & NEGATIVE \\
T8 & Quantity (09) & Education and Outreach (18) & 0.0 .066 & POSITIVE \\
T9 & EPA Method (10) & Quality Model (13) & 0.0066 \\
T10 & Quantity (09) & EPA Method (10) & 0.0075 & NEGATIVE \\
T11 & Infrastructure Inventory (12) & Site-specific Strategies (19) & 0.0094 & POSITIVE \\
T12 & Author as Consultant (03) & Site-specific Strategies (19) & 0.0134 & POSITIVE \\
T13 & Quantity (09) & Infrastructure Inventory (12) & 0.0137 & POSITIVE \\
T14 & Author as Consultant (03) & MS4 (06) & 0.0138 & POSITIVE \\
T15 & Author Type (02) & Infrastructure Inventory (12) & 0.0144 & N/A \\
T16 & Author Type (02) & Site-specific Strategies (19) & 0.0226 & N/A \\
T17 & Author Type (02) & MS4 (06) & 0.0256 & N/A \\
T18 & Author as Consultant (03) & Social Factors (11) & 0.0273 & NEGATIVE \\
T19 & MS4 (06) & Quantity Model (14) & 0.0296 & POSITIVE \\
T20 & EPA Method (10) & Stream Survey (17) & 0.0478 & POSITIVE \\
\hline & & & &
\end{tabular}

Positive correlations correspond to conditions where an increased occurrence of Factor A ("Yes" conditions) are correlated with an increased presence of Factor B. For example, test number T11 resulted in a statistically significant positive correlation between the variables of stormwater infrastructure inventory and site-specific strategy recommendations, shown in the contingency table in Table 3-3. 
Table 3-3: Positively correlated contingency table of stormwater infrastructure inventory, including BMPs, outfalls, and storm sewer system, against whether site-specific strategies were recommended (test T11). P-value $=0.0094$.

\begin{tabular}{ccccc}
\hline & & \multicolumn{2}{c}{ Infrastructure Inventory } & \\
\cline { 3 - 4 } & & Yes & No & Total \\
\hline Site-specific & Yes & 33 & 10 & 43 \\
Strategies & No & 8 & 12 & 20 \\
\hline & Total & 41 & 22 & 63 \\
\hline
\end{tabular}

Conversely, negative correlations describe situations where an increased presence of Factor A are correlated with a decreased presence of Factor B. This is the case for test number T3 where the presence of an MS4 municipality led to decreased occurrence of the characterization of social factors (Table 3-4).

Table 3-4: Negatively correlated contingency table of whether social factors were included in the watershed characterization against whether the plan was initiated by an MS4 municipality ("Yes") or initiated by an organization or agency ("No") (test T3). P-value $=0.0004$.

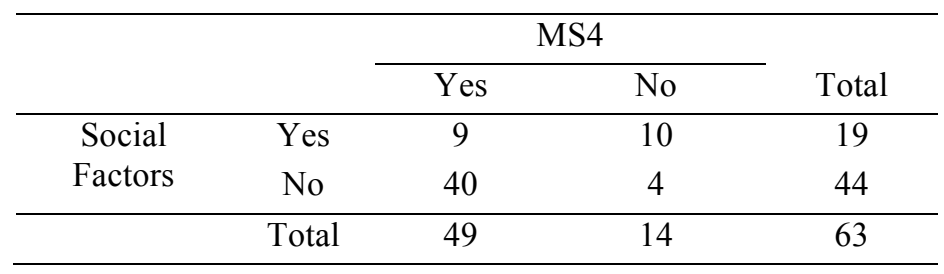

Note that only dichotomous variables can be described using positive or negative correlation. Nominal variables, such as those present in tests T15, T16, and T17, contain more than two categories and thus the correlation between variables can only be determined as statistically significant (noted as "N/A" correlation). There was no significant correlation between factors not listed in Table 3-2. Factors such as whether the watershed contained a 303(d) impaired water body were not found to have a statistically significant relationship to any other planning methodologies. Factors such as water quantity, water quality, plan authorship, infrastructure inventory, and site-specific strategies were found to have numerous correlations to other factors and planning methods. Among these, the presence of quantity or quality modeling showed the strongest correlations (lowest p-values). The results of the statistical analysis suggest correlations between different watershed factors and planning methodologies, and are further discussed in the following sections to supplement the qualitative review of planning trends. 


\subsection{Study Results AND Discussion}

Results of the study are presented in this section as a state of the practice review, as supported by existing literature, the qualitative review of 63 WMPs and WMP planning protocols, and the results of the statistical analysis. Correlations between planning factors that are introduced in this section are considered to be statistically significant, and reference the Test Numbers corresponding to the results of the statistical analysis presented in Table 3-2. The state of the practice review consists of five sections, which generally parallel the timeline of the watershed management planning process, as follows:

1. Important considerations to be made by watershed planners in the initial planning steps, including authorship, delineation of watershed study area, and use of planning protocols.

2. Data acquisition efforts regarding data availability, common data sets collected, and data management techniques.

3. Trends in watershed analysis tools and identification of emergent methodology and technology.

4. Project prioritization, implementation of improvement strategies, and plan follow-up.

5. Emerging trends in planning methodology that envision the future of watershed management planning as it continues to evolve.

\subsubsection{Initial Planning Steps}

\subsubsection{Authorship}

Watershed plans may be initiated by a municipality or by an organization, and may be developed internally through committees or externally by an agency or consulting firm. Municipalities that have city-wide watershed management programs in place include Atlanta, GA; Griffin, GA; Baltimore County, MD; Durham, NC; Greenville, NC; Lincoln, NE; and Fairfax County, VA. WMPs initiated by MS4 municipalities such as these are often developed by one or more consulting firms, as was the case for $76 \%$ of the plans reviewed (T14). Many citizen-based organizations and non-profits that are formed as watershed-based groups, in contrast to municipalities, develop the WMP internally through committees or boards. 
While WMPs developed by organizations are not constrained to political boundaries, citizenbased groups often lack the data, resources, and expertise necessary to successfully address watershed concerns; consequently, these groups may seek influence rather than the authority to implement (Gregg et al. 1998). In the review of WMPs, it was found that plans initiated by municipalities were more likely to perform hydrologic and hydraulic modeling (T19). Additionally, WMPs developed internally by the MS4 or developed by a consultant showed higher occurrences of inventorying stormwater infrastructure (T7; T15) or recommending sitespecific strategies for implementation (T12; T16) over plans developed by organizations, universities, or state agencies. Municipalities have the jurisdiction and resources to implement recommended strategies, at the cost of often being constrained to portions of the watershed that are within their political boundary.

\subsubsection{Watershed Delineation}

Watersheds can be delineated at virtually any scale, from a 5 square-mile subwatershed to a 5,000 square-mile basin. The selected scale can greatly affect the analysis potential of any watershed study, as inappropriate watershed scale has been cited as one of the primary causes of unsuccessful plan implementation (Davenport 2003; Schueler 1996). Planning efforts conducted at too small a scale may discourage integration and neglect broader watershed context (Blomquist and Schlager 2005). At broader scopes, however, localized problems and detailed analyses are sacrificed for a larger area of coverage.

The United States Geological Survey (USGS) uses a hierarchical Hydrologic Unit Code (HUC) to describe the location and relative size of a watershed, which ranges from HUC-2 at the regional level to HUC-12 at the subwatershed level. Watershed studies focusing on a smaller area - HUC-10 averaging $225 \mathrm{mi}^{2}\left(583 \mathrm{~km}^{2}\right)$, or HUC-12 averaging $40 \mathrm{mi}^{2}\left(104 \mathrm{~km}^{2}\right)$ - is the Environmental Protection Agency (EPA) recommended scale for urban studies as they are able to accommodate a higher level of detail in analysis (EPA 2008). Numerous studies have cited 50 $\mathrm{mi}^{2}\left(130 \mathrm{~km}^{2}\right)$ as the recommended maximum watershed study area because it encourages more local involvement, can provide more site-specific recommendations, and has fewer players sharing the responsibility to implement (DeShazo et al. 1996; IEPA 2007; Schueler 1996). A review of existing urban WMPs revealed a median study area of $18.1 \mathrm{mi}^{2}\left(47.0 \mathrm{~km}^{2}\right)$ and a mean of $30.7 \mathrm{mi}^{2}\left(79.4 \mathrm{~km}^{2}\right)$ (Figure 3-2). 


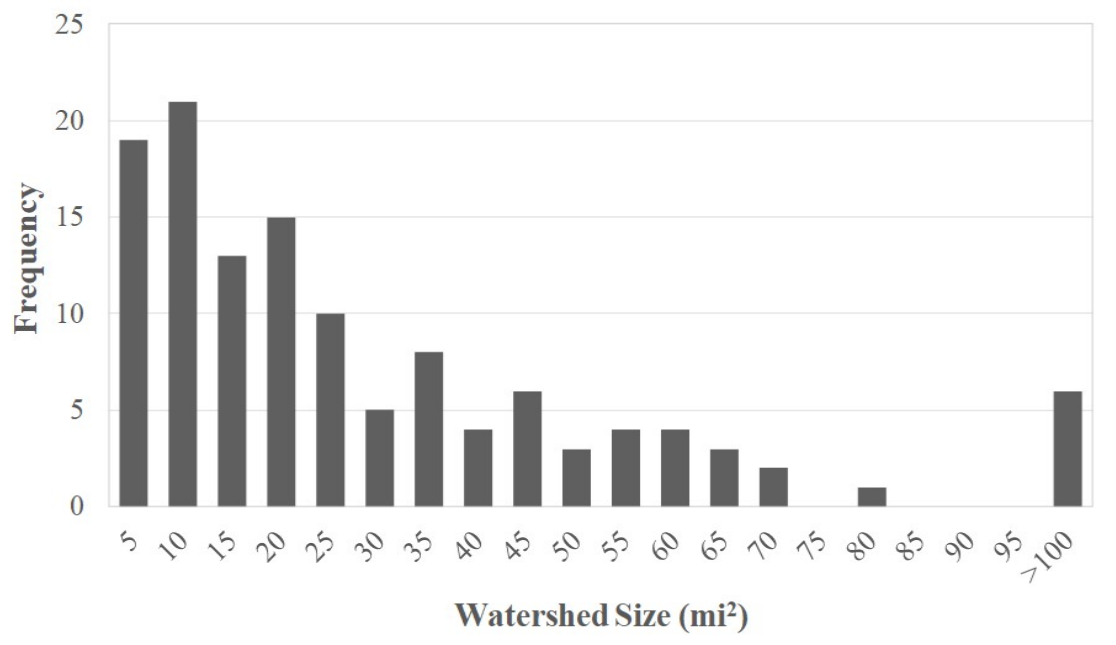

Figure 3-2: Watershed size distribution for 124 urban WMPs. The final column, ">100", includes all WMPs with watershed study areas greater than $100 \mathrm{mi}^{2}$, up to a maximum of $250 \mathrm{mi}^{2}$.

While Davenport (2003) recommends the use of HUC to define the watershed, Arnold (2010) claims the HUC classification system is a convenience that may not accurately represent physical drainage patterns. In place of HUC, watershed boundaries may be delineated manually or digitally by the watershed planner. A common Geographic Information System (GIS) tool, ArcHydro, available through ESRI ArcGIS (ESRI 2017), is often used to quickly delineate watersheds, particularly at a smaller scale than is covered by HUC (Whiteaker et al. 2006). However, automated tools such as ArcHydro are limited in urban areas because they do not account for altered drainage patterns due to stormwater infrastructure (Choi et al. 2011). The Doan Brook Watershed Action Plan in Cleveland, $\mathrm{OH}$ found that the watershed increased from $9.7 \mathrm{mi}^{2}$ to $11.9 \mathrm{mi}^{2}$ when the storm sewer system was incorporated into the delineation of the boundary; consequently, Doan Brook is often referred to as a "sewershed", an area of land that is drained by a storm sewer system, rather than a "watershed" (Doan Brook Watershed Partnership 2013). Manual verification of watershed boundaries using stormwater infrastructure maps and site investigations produces a more accurate representation of watershed boundaries.

Additionally, the availability of finer resolution topographic data through remote sensing such as Light Detection and Ranging (LiDAR) allows for more precise watershed and subwatershed delineation (Talebi et al. 2014). 


\subsubsection{Planning Protocols}

Multiple documents or planning manuals have been published at the state or regional level to provide step-by-step guidance on developing a WMP, and are available as a resource to watershed planners. Watershed planning protocols have been developed by numerous federal agencies, state agencies, and smaller organizations to facilitate in the creation of a WMP; examples of which include the EPA (EPA 2008), the Center for Watershed Protection (Center for Watershed Protection 2005), and the California Resources Agency (Shilling et al. 2005). Protocols such as these provide an aspect of consistency between plans, however they may also limit the plan and prevent innovation or risk-taking. Innovation and flexibility in planning processes are valuable as they can aid planners in addressing unique, local needs (Gregg et al. 1998). Additionally, many of these procedures are focused on a scientific process but may not provide guidance on how the planning steps are applied (Committee on Watershed Management 1999).

A frequently referenced methodology is a set of watershed planning guidelines developed by the EPA for states and communities based on a "watershed approach" (EPA 1995). The EPA has further identified in their comprehensive handbook the "Nine Key Elements" that are critical for developing an effective watershed plan (EPA 2008), summarized in Table 3-5.

Table 3-5: "Nine Key Elements" of watershed planning required by the EPA for plans funded by Section 319 Nonpoint Source Grants to States and Territories (EPA 2008). Also referred to as the "a" through "i" criteria.

\begin{tabular}{ll}
\hline a. & Identify causes and sources of pollution \\
b. & Estimate load reductions expected \\
c. & Describe management measures and targeted critical \\
d. & Estimate technical and financial assistance needed \\
e. & Develop an information and education component \\
f. & Develop a project schedule \\
g. & Describe interim, measureable milestones \\
h. & Identify indicators to measure progress \\
i. & Develop a monitoring component \\
\hline
\end{tabular}

This EPA method is targeted towards the reduction of nonpoint source pollution and must be addressed in watershed plans that are funded by the CWA 319(h) Nonpoint Source Grants to States and Territories program, a common source of funding for watershed planners. 12 of the 63 
WMPs reviewed followed the EPA method. These plans were found to correlate to a higher use of water quality modeling (T9). One of the requirements for the EPA method is estimation of pollutant loads (element b. listed in Table 3-5), which explains the correlation and suggests that the EPA method is successful in encouraging planners to employ water quality modeling tools. There was also a weak correlation between adhering to the EPA method and conducting a stream survey (T20), though it was not clear why this is the case, as there are no requirements in the EPA method for surveying the streams. It was additionally found that users of the EPA method did not focus on water quantity mitigation (T10). The EPA method therefore may expand the water quality focused methods and tools that planners employ, but may not encourage assessment of stormwater, flooding, or other water quantity related issues.

\subsubsection{Data Acquisition}

Characterization of the watershed is a critical component of the watershed planning process which involves data collection and analysis. Watershed characteristics generally fall into the categories of physical characteristics, such as climate, land use, soil, and topography; social characteristics, such as history, population, and demographics; water body condition; stormwater infrastructure inventory; water quality; and water quantity. The individual factors studied depends on the unique goals and characteristics of each watershed. The use of GIS for data storage, organization, and management has become the industry norm (Cox and Madramootoo 1998; St. John 2005). Data was historically more difficult to acquire and necessitated considerable time and effort; presently, sources of data are widely available online through numerous federal, state, or local databases (Wang et al. 2016).

While most WMPs consistently collect data on physical factors such as those listed previously, the social watershed characteristics of human communities are rarely the focus of the watershed plan as the "community picture" is the most difficult to quantify (Shilling et al. 2005). WMPs initiated by a municipality were less likely to characterize social factors of the watershed (T3), as were WMPs developed by a consultant (rather than an organization or agency) (T18). Based on the author's review of watershed plans, community-based organizations were more focused on characterizing the "local picture" of the watershed through describing the history, politics, demographics, and community value of the watershed. These factors can aid planners in 
understanding the potential level of involvement and level of success in those implementation strategies that might necessitate community participation and support.

In addition to describing the physical and social characteristics of the watershed, an inventory of stormwater infrastructure is critical in urban areas, particularly for older municipalities where the infrastructure is aged and the drainage patterns are unknown (Aguilar and Dymond 2014). Effective characterization of the location and condition of this infrastructure provides a better understanding of the drainage capacity of the watershed, and tools such as GIS and GPS continue to improve infrastructure mapping efforts. Closed-circuit television (CCTV), while not a novel technology, underwent advancements in the 1990's and 2000's that commercialized the use of the technology, including for stormwater pipe inspections and mapping of underground infrastructure (Romanova et al. 2013). An analysis of WMPs showed a correlation between inventorying stormwater infrastructure data and focusing on water quantity mitigation (T13), utilizing hydrologic and hydraulic modeling software (T2), as well as recommending sitespecific strategies (T11). Stormwater infrastructure data can be utilized in pipe capacity analyses and floodplain modeling, or merged with monitoring efforts, thereby improving efficiency and coordination.

The collection of watershed data through online acquisition, surveys, field investigations, or monitoring benefits the planning process by indicating the presence or location of existing problems; justifying the spending of resources for planning and implementation to taxpayers and stakeholders; and providing information towards monitoring the success of implemented strategies (EPA 2008). However, large gaps in data may make assessment difficult, as was reported by planners in Alabama who found that although an abundance of data for the watershed was available, the spatial and temporal extent of the data was limited, and significant data gaps were apparent (ALOA 2011). Other jurisdictions, such as Los Angeles County, explicitly incorporated the identification of information gaps into the planning processes to improve future data acquisition efforts (MEC Analytical Systems Inc. 2004).

While insufficient data could limit the reliability of data analysis or modeling, excessive data can also stymie watershed assessment. A shortcoming common to watershed assessments is the cataloging of data with little analysis (Shilling et al. 2005). Watershed planners occasionally 
chronicle the full extent of data available, which results in superfluous data and graphs that may not be appropriately utilized. A WMP in Alabama presented numerous graphs of available data which insinuated analysis, but the data was not effectively applied in plan recommendations; consequently, after submission of the WMP, it was decided that too many ambitious goals were set, and the plan had to be revisited to better prioritize projects (ALOA 2011). The recognition of critical data to include or discard can simplify data management and analysis, particularly in the present-day where too much data availability could become burdensome to the planning process.

\subsubsection{Tools for Watershed Assessment}

Numerous tools, methods, and technologies exist for the assessment and analysis of watershed data, spanning from comparative indices and standards of evaluation to highly technical computer models. The purpose of a watershed assessment is to organize, map, and interpret data to improve management decisions related to water quantity and water quality mitigation, as well as identify locations of potential remediation projects through field assessment (Center for Watershed Protection 2005). In particular, GIS is a tool that has been embraced by watershed planners, as it allows users to view spatial data and perform complex analyses (Johnson 2005; Seth et al. 2006). GIS can be incorporated into most other forms of watershed assessment; for example, modeling programs for hydrologic, hydraulic, and water quality analyses are increasingly being built with GIS compatibility (Salvadore et al. 2015). This study focused on analytical tools within five principal watershed assessment areas as discussed in the following sections: hydrologic and hydraulic modeling, water quality analysis, pollutant load modeling, stream assessment, and imperviousness.

\subsubsection{Hydrologic and Hydraulic Modeling}

The 1960's marked the first use of computer modeling for stormwater analysis, followed in the late 1970's by a push to further develop specialized models (Whipple et al. 1983). Hydrologic and hydraulic modeling is most frequently used by urban municipalities to aid in the mitigation of flooding and increased urban stormwater runoff. During the past decade, integrated modeling approaches that additionally address management of water supply and water quality has also emerged (Fletcher et al. 2013). Modeling software, such as HEC-RAS and HEC-HMS developed by the U.S. Army Corps of Engineers (USACE) Hydrologic Engineering Center (HEC) (U.S. 
Army Corps of Engineers 2016a; b), are commonly used in urban areas for flood inundation and floodplain studies (Teng et al. 2017). Hydrologic and hydraulic models also have the potential to aid watershed planners in targeting flood control measures though simulation of stormwater best management practices (BMPs) or other structural measures (Wang et al. 2017).

In the review of watershed plans, 36 of 63 WMPs performed a hydrologic or hydraulic modeling analysis. The use of the hydrologic and hydraulic models was significantly correlated with plans that focused on water quantity mitigation (T1), and WMPs that inventoried stormwater infrastructure were significantly more likely to develop a model (T2). There was also a negative correlation between the characterization of social factors in the WMP and the use of hydrologic and hydraulic models (T5), though it is not clear why this was the case; it is noted that there may be external factors in effect. The types of modeling software identified in WMPs reviewed are shown in Table 3-6, divided into five-year time increments.

Table 3-6: Frequency and type of hydrologic/hydraulic models used in WMPs over time (in 5-year periods). Note that some WMPs may utilize a combination of multiple models.

\begin{tabular}{lcccccccc}
\hline Model & $1986-$ & $1992-$ & $1997-$ & $2002-$ & $2007-$ & $2012-$ & Sum & Reference \\
& 1991 & 1996 & 2001 & 2006 & 2011 & 2016 & \\
\hline PSRM & 1 & 0 & 1 & 0 & 0 & 0 & 2 & (Aron 1987) \\
TR-20 & 0 & 1 & 2 & 1 & 0 & 0 & 4 & (Soil Conservation Service 1992) \\
HEC-1 & 0 & 0 & 2 & 0 & 0 & 0 & 2 & (U.S. Army Corps of Engineers 1998) \\
ICPR & 0 & 0 & 1 & 0 & 1 & 0 & 2 & (Streamline Technologies Inc. 2016) \\
HydroCAD & 0 & 0 & 0 & 0 & 1 & 0 & 1 & (HydroCAD Software Solutions 2011) \\
SWAT & 0 & 0 & 0 & 0 & 1 & 0 & 1 & (Arnold et al. 2012) \\
AGWA & 0 & 0 & 0 & 0 & 0 & 1 & 1 & (USDA-ARS et al. 2015) \\
LSPC & 0 & 0 & 0 & 0 & 0 & 1 & 1 & (Tetra Tech Inc. 2009) \\
HEC-RAS & 0 & 0 & 2 & 2 & 3 & 1 & 8 & (U.S. Army Corps of Engineers 2016a) \\
SWMM & 0 & 0 & 0 & 3 & 3 & 2 & 8 & (Rossman 2015) \\
HEC-HMS & 0 & 0 & 0 & 0 & 4 & 4 & 8 & (U.S. Army Corps of Engineers 2016b) \\
\hline Sum & 1 & 1 & 8 & 6 & 13 & 9 & 38 & \\
\hline
\end{tabular}

A total of eleven different types of models were used. Among these, HEC-RAS, HEC-HMS, and the Storm Water Management Model (SWMM) (Rossman 2015) were the most common, particularly in WMPs developed after the early 2000's. Earlier models included the Penn State Runoff Model (PSRM) (Aron 1987) and TR-20 (Soil Conservation Service 1992). While models such as PSRM, TR-20, and the Illinois Urban Drainage Simulator (ILLUDAS) (Terstriep and Stall 1974) have lost popularity, others including SWMM, Hydrological Simulation Program - 
Fortran (HSPF) (Bicknell et al. 1997), and HEC-based models have remained relevant through the years, undergoing numerous updates and improvements (Salvadore et al. 2015; Whipple et al. 1983; Wurbs 1994). This shift to models that are more widely used and accepted, such as SWMM and HEC-RAS, may be a result of the increased computational capacity and inclusion of interdisciplinary elements over older models that were purely engineering or economic in nature (Mirchi et al. 2010). Future model development is likely to manifest in the form of advanced modeling capabilities that incorporate complex interdisciplinary elements such as climate change modeling (Fletcher et al. 2013).

\subsubsection{Water Quality Analysis}

Water quality analysis is highly driven by regulations, most notably in urban areas as progress towards TMDL Waste Load Allocations must be demonstrated in annual MS4 permit reports. To address these regulations, watershed planners may collect water quality data and/or perform pollutant load modeling. Water quality data, including physical, chemical, and biological parameters, can be obtained through existing local water quality monitoring programs, volunteer monitoring, past studies, and state or regional agencies. Long-term water quality data aids planners by indicating trends in water body health or by explaining cause-and-effect situations (Espinosa-Villegas et al. 2005).

The identification of pollutant sources is frequently an outcome of water quality analyses. Water quality constituents may be a result of point or nonpoint source pollution. Point source pollution is often identified as septic systems, combined sewer overflows (CSOs), or National Pollutant Discharge Elimination System (NPDES) permit dischargers, among others. Nonpoint source pollution is more difficult to identify, and is generally estimated based on land use and land cover. To further improve the identification of pollutant sources in the watershed, source tracking studies are on the forefront of water quality analyses (Bushon et al. 2017). Microbial source tracking and fluorometry (fluorescence spectroscopy) monitoring are among the types of source tracking used. Microbial source tracking was performed (or recommended) for watershed studies including Clearwater, Florida (Parsons 2001); Atlanta, Georgia (Atlanta Regional Commission 2011); and Bergen County, NJ (Rutgers Cooperative Extension Water Resources Program 2013). The goal of these studies was principally to determine the origins, prevalence, and/or rate of transport of human pathogens in streams. Source tracking helps planners determine 
whether microbes are anthropogenic or animal, and can trace the spatial extent of pathogens to identify pollutant sources originating from contributing water bodies and tributary streams. There was insufficient information on the use of microbial source tracking to conduct a statistical analysis on these data.

\subsubsection{Pollutant Load Modeling}

A common tool for assessing water quality across a watershed is through pollutant load modeling, which can simulate watershed functions to fill in data gaps, identify pollutant sources, model implementation strategies, or assess future conditions (EPA 2008; Wurbs 1994). These models rely on several factors - primarily land use - to estimate the total pollutant loading by watershed or catchment area, and can be tailored towards specific pollutants; although these models are typically targeted towards modeling nonpoint source pollution as this is more difficult to identify and remediate than point source pollution (Carle et al. 2005). Pollutant load modeling can additionally be used to estimate pollutant removal by simulating various BMPs and land use change scenarios (Wang et al. 2017). However, there are limitations in the application of pollutant load models due to uncertainty in the removal efficiencies of BMPs, as many studies have shown that BMP removal efficiencies vary greatly based on construction and maintenance practices, as well as uncertainties in design (Barrett 2008; Strecker et al. 2001).

It was found that plans focusing on water quality mitigation were more likely to develop a water quality model (T6) over plans that identified water quantity mitigation goals (T4). Pollutant load modeling was performed in 43 of the 63 WMPs reviewed in this study, and the methods used can be broadly categorized as either calculation-based, spreadsheet-based, or GIS-based models. Calculation-based models frequently used the Simple Method, a lumped-parameter empirical model that estimates pollutant load using basic inputs of land area, land use, and precipitation (Schueler 1987). Spreadsheet-based models, while still largely based on calculations such as the Simple Method, allow for additional data inputs and simulation of BMPs. Common spreadsheetbased models observed in the review of WMPs include HSPF, the Source Loading and Management Model (WinSLAMM) (Pitt et al. 1997), the Spreadsheet Tool for Estimating Pollutant Loads (STEPL) (Tetra Tech Inc. 2017), and the Loading Simulation Program in C++ (LSPC) (Tetra Tech Inc. 2009). GIS-based models incorporate the spreadsheet-based calculations into a GIS environment, thereby improving the modeling and simulation 
capabilities. Common GIS-based models observed in WMPs include SWMM, Soil and Water Assessment Tool (SWAT) (Arnold et al. 2012), PLOAD (CH2M Hill 2001), and numerous proprietary models. Of the WMPs in this study that performed pollutant load analysis, $42 \%$ used Simple Method calculations, 26\% used a spreadsheet-based model, and 33\% used a GIS-based model. The distribution of these model types is shown in Table 3-7 by five-year time increments.

Table 3-7: Frequency and type of pollutant loading models used by WMPs over time (in 5-year periods). Model types are separated into calculation-based approximations, spreadsheet-based models, or GIS-based models. "Percent" indicates the percentage of WMPs that used a pollutant load model out of all WMPs.

\begin{tabular}{lccccccc}
\hline $\begin{array}{l}\text { Model } \\
\text { Type }\end{array}$ & $1986-$ & $1992-$ & $1997-$ & $2002-$ & $2007-$ & $2012-$ & Sum \\
Calculation & 1 & 3 & 2 & 2 & 4 & 6 & 18 \\
Spreadsheet & 0 & 0 & 0 & 0 & 5 & 6 & 11 \\
GIS & 0 & 0 & 1 & 4 & 4 & 5 & 14 \\
\hline Sum & 1 & 3 & 3 & 6 & 13 & 17 & 43 \\
\hline Percent & $100 \%$ & $100 \%$ & $43 \%$ & $60 \%$ & $72 \%$ & $74 \%$ & \\
\hline
\end{tabular}

Spreadsheet-based and GIS-based models first appeared in the study WMPs in the early 2000's. Although the occurrence of these has increased, simple calculation-based models have not disappeared entirely. The distribution of the different types of models over time appears to be balanced, particularly in the past decade, suggesting that model selections are made with equal prevalence. Furthermore, the overall use of pollutant models was observed to increase over time, shown in the increasing percentage of WMPs using pollutant load models since the early 2000's. It should be noted that the high percentage of water quality model usage between 1986 and 1996 is due to lower sample sizes in these time periods, and does not necessarily suggest that models were more widely used prior to 1996.

The most common pollutant load model employed by the WMPs studied was STEPL, used by 14\%; additionally, numerous proprietary models and GIS-based models are largely derived from STEPL. Lake County, IL, for example, performed pollutant load analysis using a water quality model derived from STEPL (Lake County Stormwater Management Commission and Northwater Consultants 2014). The spatial distribution, at the parcel to catchment scale, for modeled annual sediment, phosphorous, bacteria, and chloride loading was displayed as a risk 
map that highlighted zones of the watershed that have the potential to produce higher loadings of the identified pollutants of concern.

\subsubsection{Stream Assessment}

The assessment of stream condition, health, and habitat is a fundamental step towards making sound natural resource management decisions (Somerville and Pruitt 2004). Stream assessments ranging from qualitative visual assessments to more comprehensive quantitative exercises might be used to address any number of purposes including the management of fish and wildlife, assessment of drinking water sources, regulatory compliance, and watershed or land use planning (Somerville and Pruitt 2004). For the purposes of watershed planning, a visual assessment of the stream corridor can provide information towards characterizing current stream conditions, monitoring the effects of restoration strategies, identifying specific locations of concern, and familiarizing local stakeholders, decision makers, or agency personnel with the stream (Center for Watershed Protection 2005; EPA 2008).

In the review of watershed plans, 42 WMPs performed a stream assessment survey or stream condition inventory. Methods and factors surveyed generally consisted of one (or more) categories of: channel classification, geomorphic assessment, bank stability and erosion, riparian vegetation, and stream habitat. Bank stability or bank erosion was the most common assessment, performed in 16 WMPs, followed by riparian vegetation (11), channel condition (8), and stream habitat (8). The channel condition factor describes the extent of channel modification, such as natural, re-routed, or piped. Numerous standard methods and assessment protocols exist to guide the stream survey process. In the review of WMPs, a total of 20 unique stream assessment protocols, methods, or indices were referenced; these include methods such as the Bank Erosion Hazard Index (BEHI) (Rosgen 2001), Stream Visual Assessment Protocol (SVAP) (USDA 1998), and Rapid Stream Assessment Technique (RSAT) (Galli 1996). Approximately one-third of WMPs that performed a stream assessment did not follow an established protocol, instead performing a visual inventory through field surveys using GPS or GIS to catalog photographs, survey notes, or other stream features.

Results of the stream assessment are often used by municipalities to identify potential stream restoration sites or establish benchmark conditions for future monitoring. For example, 
watershed planners in Atlanta, GA conducted numerous field investigations at over 300 points in the Peachtree Creek watershed to identify hydrologic and anthropogenic alterations, riparian buffer condition, BEHI, and habitat, among other metrics of assessment (BC/DHA 2017). These indices were mapped along the streams to identify locations where restoration projects could be implemented, and some channel condition indices were additionally input into a planning-level water quality model. However, the applicability of stream assessment outcomes is limited. Standard metrics of evaluation are not a substitute for determining causes of impairment or appropriate restoration actions that should occur; for example, it is misguided to assume that bank erosion is universally undesirable, as it has been shown to have benefits as well as costs to the dynamic ecological processes of a stream (Rubin et al. 2017). Additionally, the selection of restoration sites is often highly limited in urban areas by adequate access to the stream, availability of land, and the presence of other facets of infrastructure, among other challenges (Landers 2010).

\subsubsection{Imperviousness}

The amount of impervious cover in a watershed is often used as an indicator of overall stream health, as it is relatively simple to measure and has been shown to correlate with water quality degradation (Booth et al. 2002; Glick 2009). A metric frequently referenced by watershed planners to describe the level of anticipated water body impairment is the Impervious Cover Model (ICM), which predicts that stream degradation occurs in response to $10 \%$ impervious area in the watershed, with severe impairment occurring after 30\% imperviousness (Arnold and Gibbons 1996). There were 16 WMPs in the study that cited the ICM or a similar relationship between stream health and impervious cover. Tools for estimating impervious cover have advanced from aerial photography and remote sensing to direct calculation using GIS. Among the different methods of estimating impervious cover, the functional difference between total impervious area (TIA) and effective impervious area (EIA), sometimes referred to as the directly connected impervious area (DCIA), is now being realized and incorporated into watershed planning (Brabec 2009), as DCIA and EIA provide more mechanistic representation of watershed function (Ebrahimian et al. 2016; Lee and Heaney 2003).

Watershed planners have applied the estimation of impervious cover as a surrogate measurement for stream health (FB Environmental Associates 2014), as a factor in the prioritization of 
subwatersheds or catchments for restoration strategies (AKRF Inc. 2012), or as a predictor for channel enlargement (City of Austin 2016). While the assessment of watershed imperviousness can be a beneficial tool, planners are limited in the restoration strategies they can employ. The City of Fairfax, VA modeled stormwater flows resulting from impervious cover scenarios and discovered that a $50 \%$ reduction in impervious area would be required to achieve significant reduction in flows, which would necessitate substantial changes to the existing built-out landscape (The Louis Berger Group Inc. et al. 2005). Others have sought to prioritize the disconnection of impervious through incentives such as "tree credits" (Philadelphia Water Department 2005), or through policy application (Center for Watershed Protection et al. 2001). In Maine, a state-wide impervious cover (IC) TMDL has been issued that identifies local IC targets, such as a goal of $8 \%$ effective impervious area in the Topsham Fair Mall watershed (FB Environmental Associates 2014).

\subsubsection{Project Implementation}

Recommendations for improvement strategies are often a combination of monitoring, education and outreach, policy, infrastructure improvements, and structural BMPs. The selection of appropriate strategies will depend on assessing existing programs, the availability of resources, and the needs of the watershed. Two important factors that will carry the plan from preliminary planning through to implementation are whether the plan outlines realistic mechanisms of enforcement (Schueler 1996) and if the watershed plan consider how projects will be implemented given limited resources and the availability of land. A WMP in Juneau, AK found that the primary factors that led to no implementation of the plans were a lack of funding, enforcement, awareness, and cooperation (Koski and Lorenz 1999). In contrast, Griffin, GA attributes their success in improved planning and management to stormwater utility funding that allowed the division to get organized before the planning process commenced (Kaplan and Watson 2013).

It is critical that planners extend the outcomes of the watershed analysis into the project implementation phase. Analysis outcomes inform the prioritization of strategies - a necessary step towards implementation for jurisdictions faced with limited resources. Considerations for project prioritization observed in watershed plans include: 
- Cost,

- Land availability,

- Effectiveness of strategy type,

- Short-term versus long-term solutions, and

- Priority catchments or subwatersheds.

Subwatershed prioritization allows planners to determine locations within the watershed that warrant a greater allocation of resources. Pollutant load modeling completed on a subwatershed basis can identify locations within the watershed that may be at a higher risk of producing certain pollutants or increased runoff. Other factors tailored to local concerns might be overlain in order to prioritize project implementation by subwatershed. A robust prioritization and ranking scheme was developed in Austin, TX that generates "problem scores" for issues related to flooding, erosion, and water quality (City of Austin 2016). A similar prioritization scheme was applied in Fairfax County, VA based on watershed impact indicators, source indicators, priority subwatersheds, sequencing (upstream versus downstream projects), and "implementability" (F. X. Browne Inc. et al. 2011). While overall project effectiveness is important for the success of implementation, newer management programs are focusing more on the feasibility of projects over other prioritization factors (Ormsbee and McAlister 2014). Often, the obtainability of undeveloped public land and sufficient funding are the principal factors limiting implementation efforts.

It was found that the plan outcomes and implementation recommendations differed between plans that were a first-time effort versus those that had prior experience developing WMPs, a more robust department or planning group dedicated to stormwater or watershed planning, a reliable source of funding, and/or greater access to data and analytical tools. For example, the Watkins Creek Watershed Management Plan in St. Louis, MO developed in 2012 was commenced by a partnership of organizations and was supported by state funding (Rollins and Johnson 2012). Few watershed studies were completed in the past, and the partnership was limited by access to funding, data, and authority to implement; therefore, the plan resulted in only general recommendations. In comparison, the Antelope Creek Watershed Basin Management Plan was also developed in 2012, and was initiated and funded by the City of Lincoln, NE (EA Engineering Science and Technology Inc. 2012). Prior to this plan, the City 
had completed previous plans for other watersheds in the City, dating back to 2000. The access to reliable funding, data, and technological tools, as well as the knowledge from prior planning efforts, allowed the City to recommend more site-specific strategies with the capacity to implement. While the year in which the WMP was developed was a factor that was initially hypothesized to correlate to other planning methodologies, this trend in planning efforts was observed to be a more explanatory relationship, as there were no identified trends based on the year in which the WMP was developed.

Sequent to project implementation is monitoring and plan follow-up to track the implementation of recommended projects and to evaluate the successes and failures of planning outcomes. This adaptive management technique allows planners to better inform future efforts. The Center for Watershed Protection suggests revisiting WMPs on a rolling five-year cycle (Schueler 1996); however most plans take several years to implement, making the five-year cycle difficult to achieve (Ormsbee and McAlister 2014). While some WMPs do periodically update the plans, few plans were found to complete meaningful evaluation of successes and failures. Adaptive management in watershed planning is critical for improvement, as watershed conditions are dynamic.

\subsubsection{Emerging Trends in Watershed Management Planning}

Current watershed planning has often been shown to possess risk aversion that may not adequately promote adaptive management (Arnold 2010). One possible cause for risk aversion in watershed planning is that there are few incentives for risk-taking and innovation (Allan et al. 2008). A community-based watershed group in Oregon expressed that their willingness to explore alternative solutions was deterred when they were singled out for praise and, under the spotlight, became dissuaded from taking more innovative or risky approaches (Gregg et al. 1998). Another factor that might contribute to risk aversion is strict adherence to watershed planning guidance manuals and standard procedures, where planners become inhibited by a finite list of tools, methods, and recommendations that they can employ. Innovation and experimentation in watershed planning can improve future efforts by exploring new options and by assessing successes and failures. 
An example of innovation in watershed planning is the Conway Urban Watershed Framework Plan, which has received numerous awards and recognition for planning and design and was developed to create a "reconciliation landscape" that fuses green infrastructure with a livable urban landscape (University of Arkansas Community Design Center et al. 2016). While the plan is not scientifically-based in the standard watershed management planning process, innovative designs such as water treatment art parks, urban eco-farms, parking gardens, and floating biomats are among the recommended solutions. The watershed management field is, in many ways, still in its infancy, and many acknowledge that each watershed plan or management action is its own experiment (Center for Watershed Protection 2005; Shilling et al. 2005). Implementing innovative solutions, evaluating and monitoring the successes and failures of those solutions, and reporting those outcomes allows for others to learn from and adapt to those techniques. Failures should be documented and reflected on by watershed planners to the same degree as successes.

A shift in focus from stormwater and flooding towards water quality, community involvement, and ecological issues was observed, consistent with the findings of watershed management literature (Davenport 2003; Doerfer and Urbonas 2004). Older watershed plans, such as those developed in Cullman County, AL (Cullman County 1976) or Montgomery County, PA (Montgomery County 1997), were more focused on mitigation of flooding or stormwater issues, and often provided specific design alternatives due to the limited scope of the plans. Conversely, more recent watershed plans have a greater focus on water quality and interdisciplinary issues. This may be due to the increased role of water quality regulations. Watershed planning is highly responsive to regulations, particularly for WMPs developed for urban municipalities, and planning efforts are often initiated under the threat of regulatory action (Born and Genskow 2001). MS4 permit requirements, NPDES requirements, and TMDLs are among the water resources regulations that municipalities must address. Figure 3-3 compares the number of TMDLs issued per year to the number of WMPs developed (of 124 WMPs within the scope of the study). 


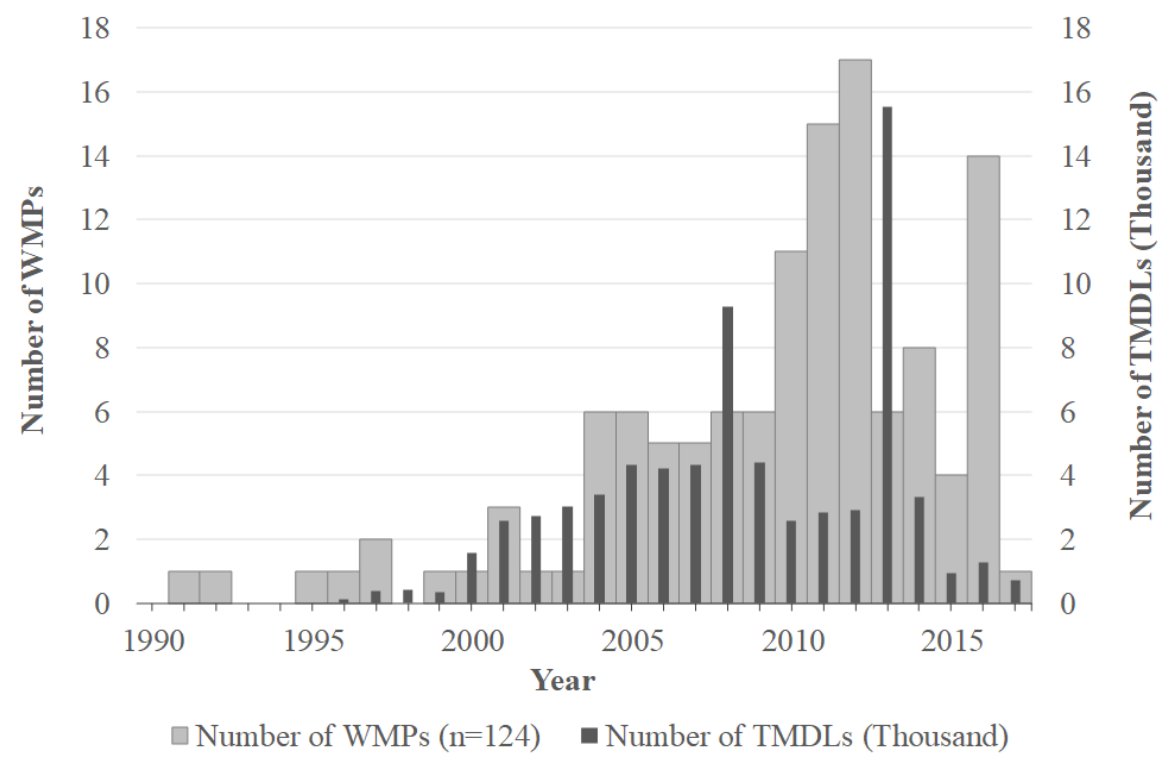

Figure 3-3: Frequency of WMP development plotted with the number of TMDLs issued nationwide, by year. Number of WMPs include all WMPs within the scope of the study (n=124). Number of TMDLs does not refer to number of impaired water bodies; there may be multiple TMDLs issued for a single water body in a given year (EPA 2017b).

A peak in number of WMPs can be observed approximately 3 years following a peak in TMDLs, which may suggest that WMPs were developed in response to the issuance of a TMDL.

Watershed plans are likely to continue to respond to the changing regulatory environment by accordingly adjusting goals, analysis, and recommendations. This was observed in the WMPs reviewed, as more plans focused on water quality goals rather than water quantity, as the MS4 and TMDL programs focus on water quality improvements and not flood control.

Watershed plans will also need to address future conditions related to population growth, land use change, and climate change. While numerous plans are already incorporating future land use and population growth into planning processes, plans need to be robust to significantly altered future conditions. The effects of climate change on urban watersheds is a particular area of planning, modeling, and research in watershed management that warrants greater attention (Olsson et al. 2013; Semadeni-Davies et al. 2008; Wang et al. 2016). It has been postulated that watershed planning may be the leader in pushing for watershed-scale climate change models, as the currently accepted models are at larger regional or global scales (Arnold 2010). The improved adaptability of models and planning measures to climate change is critical, as the traditionally used design storms (i.e. 10-year or 100-year) may no longer accurately represent 
their respective return intervals, and the impacts of this at a localized scale is uncertain (Willems et al. 2012). Use of increasingly sophisticated data and models is necessary as one of the vulnerabilities of watershed plans is the failure to appropriately utilize available climate change data and models (Arnold 2010). Watershed planners will need to take advantage of advanced modeling and technology, as well as create the demand for improved technology.

\subsection{CONCLUSIONS AND IMPLICATIONS}

Watershed management planning has evolved considerably since its inception in the early $20^{\text {th }}$ century. Watershed approaches are becoming more focused on local participation and the complex relationships between water resources, ecology, biology, and environmental health. These approaches, if effectively employed, can benefit urban municipalities by informing the allocation of resources and improvement strategies. Numerous trends in planning methodologies were identified for various aspects of the planning process, from plan inception to project implementation and follow-up. Among these, trends in data management techniques, modeling programs, and technology are a recognizable driving force. The following summarizes the primary trends identified in the study.

- WMPs developed by a consultant or a municipality were more likely to inventory stormwater infrastructure, perform hydrologic and hydraulic modeling, and recommend site specific strategies, while plans developed by organizations focused more on the community picture through characterizing the social factors of the watershed.

- A common planning protocol is the EPA "Nine Key Elements" method, which resulted in higher occurrences of water quality modeling and stream assessments; however, there was a lower focus on water quantity mitigation in the plans that used this method.

- The collection of stormwater infrastructure data was highly correlated to performing hydrologic and hydraulic modeling and to recommending site-specific strategies over general recommendations.

- Trends in the types of hydrologic and hydraulic models were observed, most notably in the increased use of HEC-RAS, HEC-HMS, and SWMM over the past decade. 
- The use of pollutant load modeling has been gradually increasing, though no clear preference for a type of model (either calculation-, spreadsheet-, or GIS-based) was observed.

- The prioritization of projects prior to implementation is based in a common set of factors; however, the "implementability" of projects, such as the availability of land, funding, and personnel, has been of increasing importance.

- Few plans were observed to take innovative or risky approaches in the analysis or recommendations of improvement strategies; plans may be further hindered or limited in scope by strict adherence to planning protocols.

- WMPs were observed to be highly responsive to regulations, as indicated by a response to TMDLs. It is conjectured that regulations will continue to drive the future of watershed planning.

The tools, techniques, and methodologies identified in this study can be a useful resource for municipalities and watershed planners. It is emphasized, however, that this study was limited in scope to digitally available plans, and did not attempt to evaluate the successes or failures of the plan outcomes. To understand the effectiveness of the planning methodologies, plan follow-up and evaluation of implemented strategies will need to occur. Additionally, the scope of this study was largely limited by the availability of digital WMPs and the popularity in developing WMPs has surged in more recent years; consequently, this study resulted in an approximately 15- to 20year period of study. A similar study conducted 15 years in the future that revisits the identified trends in planning methodology would produce a more long-term analysis of watershed planning. Watershed management planning is a promising field for urban municipalities, as the planning processes, technology, modeling programs, and assimilation of interdisciplinary fields of study continue to progress. 


\section{Conclusion}

\subsection{IMPLICATIONS}

This study has identified existing and emerging trends in watershed management planning methodologies and procedures, as employed by urban municipalities. 63 WMPs were qualitatively reviewed based on planning processes, followed by a statistical analysis of planning factors. The qualitative review and statistical analyses were presented as a state of the practice review of watershed management planning, supplemented by existing literature and planning protocols or manuals. Numerous trends in planning methodologies were identified for various aspects of the planning process; specifically, initial planning steps, data acquisition, tools for watershed assessment, project implementation, and emerging trends were discussed. Among these, trends in data management techniques, modeling programs, and technology are a recognizable driving force. It was also observed that watershed approaches are becoming more focused on local participation and the complex relationships between water resources, ecology, biology, and environmental health.

The tools, techniques, and methodologies identified in this study can be a useful resource for municipalities and watershed planners. These approaches, if effectively employed, can benefit urban municipalities by informing the allocation of resources and improvement strategies. The watershed management planning process has been evolving based on improved technologies, social trends, and changing regulations. This study assessed changes and trends to the planning process which can benefit future planners through adaptive management techniques.

\subsection{FUtURE WORK}

While this study reviewed trends in planning processes, the evaluation of the successes or failures of plan outcomes was not attempted. To understand the effectiveness of the planning methodologies, plan follow-up and evaluation of implemented strategies will need to occur. Future research should be conducted that evaluates the effectiveness of planning methodologies to better inform future efforts. Interviews or surveys conducted with municipalities or other

planning organizations that have developed a WMP would aid in assessing the level of success in various planning efforts, as well as providing insight into whether certain plan recommendations 
were employed. This is of particular importance as few plans reviewed in this study reported that plan-follow up or assessment was completed.

Additionally, the scope of this study was largely limited by the availability of digital WMPs. As the popularity in developing WMPs has surged in more recent years, and as many older WMPs may not have been converted to digital format or made available to public use, this study resulted in an approximately 15- to 20-year period of study. Future research conducted approximately 15 years in the future that revisits the identified trends in planning methodology would produce a more long-term analysis of watershed planning. Future studies additionally should continue to investigate existing and emerging technologies, as improvements to data availability and technological tools have been rapidly progressing in recent decades.

\subsection{FINAL WORDS}

Watershed management planning is a promising field for urban municipalities, as the planning processes, technology, modeling programs, and assimilation of interdisciplinary fields of study continue to progress. This study attempts to evaluate the state of the practice of watershed management planning to equip urban municipalities and watershed planners with the tools and knowledge to develop, understand, and employ a WMP. It is important to dynamically adapt to changing technology, tools, regulations, and social trends, as well as future land use changes and climate change, in order to improve the health and safety of the public and the environment. 


\section{REFERENCES}

Aguilar, M. F., and Dymond, R. L. (2014). "Innovative Technologies for Storm-Water Management Programs in Small Urbanized Areas." Journal of Water Resources Planning and Management, 140(11), 4014029.

AKRF Inc. (2012). “Mianus River Watershed Based Plan.” The South Western Regional Planning Agency, Stamford, CT.

Allan, C., Curtis, A., Stankey, G., and Shindler, B. (2008). "Adaptive Management and Watersheds: A Social Science Perspective." Journal of the American Water Resources Association, 44(1), 166-174.

ALOA. (2011). "Parkerson Mill Creek Watershed Management Plan." Alabama Cooperative Extension System, Auburn, AL.

Arnold, C. A. (2010). “Adaptive Watershed Planning and Climate Change." Environmental and Energy Law and Policy Journal, 5, 417-488.

Arnold, C. L., and Gibbons, C. J. (1996). "Impervious Surface Coverage: The Emergence of a Key Environmental Indicator." Journal of the American Planning Association, 62(2), 243258.

Arnold, J. G., Kiniry, J. R., Srinivasan, R., Williams, J. R., Haney, E. B., and Neitsch, S. L. (2012). "Soil \& Water Assessment Tool (SWAT) Input/Output Documentation Version 2012." Texas Water Resources Institute.

Aron, G. (1987). Penn State Runoff Model for IBM PC. Dept. of Civil Engineering and Institute for Research on Land and Water Resources, Pennsylvania State University.

Atlanta Regional Commission. (2011). "Proctor Creek - Headwaters to Chattahoochee River: Watershed Improvement Plan.” Atlanta, GA.

Barrett, M. E. (2008). "Comparison of BMP Performance Using the International BMP Database." Journal of Irrigation and Drainage Engineering, 134(5), 556-561.

BC/DHA. (2017). "Peachtree Creek Watershed Improvement Plan.” Department of Watersehd Management, Atlanta, GA.

Bicknell, B. R., Imhoff, J. C., Kittle, Jr., J. L., Donigian, Jr., A. S., and Johanson, R. C. (1997). "Hydrological Simulation Program: FORTRAN User's Manual for Version 11.” U.S. Environmental Protection Agency, National Exposure Research Laboratory, Athens, GA. 
Blomquist, W., and Schlager, E. (2005). "Political Pitfalls of Integrated Watershed Management.” Society and Natural Resources, 18(2), 101-117.

Booth, D. B., Hartley, D., and Jackson, R. (2002). "Forest Cover, Impervious-Surface Area, and the Mitigation of Stormwater Impacts." Journal of the American Water Resources Association, 38(3), 947-835.

Born, S. M., and Genskow, K. D. (2001). Toward Understanding New Watershed Initiatives: A Report from the Madison Watershed Workshop. Madison, WI.

Brabec, E. A. (2009). "Imperviousness and Land-Use Policy: Toward an Effective Approach to Watershed Planning." Journal of Hydrologic Engineering, 14(4), 425-433.

Browner, C. M. (1996). Watershed Approach Framework. (EPA Publication No. 840-S-96-001), U.S. Environmental Protection Agency.

Bushon, R. N., Brady, A. M. G., Christensen, E. D., and Stelzer, E. A. (2017). "Multi-Year Microbial Source Tracking Study Characterizing Fecal Contamination in an Urban Watershed." Water Environment Research, 89(2), 127-143.

Carle, M. V., Halpin, P. N., and Stow, C. A. (2005). "Patterns of Watershed Urbanization and Impacts on Water Quality." Journal of the American Water Resources Association (JAWRA), 41(3), 693-708.

Center for Watershed Protection. (2005). A User's Guide to Watershed Planning in Maryland.

Center for Watershed Protection, Macris Hendricks and Glasock Inc., and Environmental

Systems Analysis Inc. (2001). "Watts Branch Watershed Study and Management Plan Final Report." City of Rockville Department of Public Works, Rockville, MD.

CH2M Hill. (2001). “PLOAD Version 3.0 User's Manual.” U.S. Environmental Protection Agency.

Chess, C., and Purcell, K. (1999). "Policy Analysis Public Participation and the Environment: Do We Know What Works?” Environmental Science \& Technology, 33(732), 2685-2692.

Choi, Y., Yi, H., and Park, H.-D. (2011). “A new algorithm for grid-based hydrologic analysis by incorporating stormwater infrastructure." Computers \& Geosciences, 37(8), 1035-1044. City of Atlanta. (2017). "Atlanta's Watersheds." Office of Watershed Protection, Atlanta, GA, $<$ http://www.atlantawatershed.org/inside-dwm/offices/watershed-protection/>. City of Austin. (2016). "Watershed Protection Master Plan.” Watershed Protection Department, Austin, TX. 
City of Lincoln. (n.d.). "Watershed Master Plans."

$<$ https://www.lincoln.ne.gov/city/pworks/watershed/master-plan/> (Mar. 23, 2017).

Committee on Watershed Management. (1999). New Strategies for America's Watersheds.

National Research Council, National Academy Press, Washington D.C.

Cox, C., and Madramootoo, C. (1998). "Application of Geographic Information Systems in Watershed Management Planning in St. Lucia." Computers and Electronics in Agriculture, 20, 229-250.

Cullman County. (1976). "Watershed Plan and Environmental Impact Statement for Watershed Protection and Flood Prevention: Mud Creek." Cullman County, AL.

Davenport, T. E. (2003). The Watershed Project Management Guide. Lewis Publishers.

DeShazo, R. P., Garrigan, P., and Merrimack River Initiative. (1996). Watershed Connections, Lessons Learned in Subwatersheds of the Merrimack River Watershed: The Nashua, Souhegan and Stony Brook Watersheds. Wilmington, NH.

Doan Brook Watershed Partnership. (2013). "Doan Brook Watershed Action Plan." Cleveland, $\mathrm{OH}$.

Doerfer, J. T., and Urbonas, B. R. (2004). "Urban Watershed Master Planning for Stream Protection in the Denver Metropolitan Area." Protection and Restoration of Urban and Rural Streams, American Society of Civil Engineers, 51-60.

Durham. (2017). “Durham's Watersheds.” Public Works Department, Durham, NC, $<$ https://durhamnc.gov/705/Durhams-Watersheds $>$.

EA Engineering Science and Technology Inc. (2012). "Antelope Creek Watershed Basin Management Plan." City of Lincoln Watershed Management, and the Lower Platte South Natural Resources District, Lincoln, NE.

Ebrahimian, A., Wilson, B. N., and Gulliver, J. S. (2016). "Improved methods to estimate the effective impervious area in urban catchments using rainfall-runoff data." Journal of Hydrology, 536, 109-118.

EPA. (1995). Watershed Protection: A Statewide Approach. Office of Water, U.S.

Environmental Protection Agency, Washington D.C.

EPA. (2003). "Watershed Analysis and Management (WAM) Guide for States and Communities." Office of Water, U.S. Environmental Protection Agency.

EPA. (2008). Handbook for Developing Watershed Plans to Restore and Protect Our Waters. 
Office of Water, U.S. Environmental Protection Agency, Washington D.C.

EPA. (2013). “A Quick Guide to Developing Watershed Plans to Restore and Protect Our Waters." 59.

EPA. (2017a). “319 Grant Program for States and Territories.” Polluted Runoff: Nonpoint Source Pollution, <https://www.epa.gov/nps/319-grant-program-states-and-territories> (Mar. 10, 2017).

EPA. (2017b). "National Summary of Impaired Waters and TMDL Information.” U.S.

Environmental Protection Agency, <https://iaspub.epa.gov/waters10/attains_index.home> (May 1, 2017).

Espinosa-Villegas, C. O., Just, C. L., and Schnoor, J. L. (2005). "Sustainable Watershed Management: Impacts of a 30-Year Historical Record of Water Quality of the Iowa River." Managing Watersheds for Human and Natural Impacts: Engineering, Ecological, and Economic Challenges, 1741-1748.

ESRI. (2017). “ArcGIS 10.5.1.” Environmental Systems Research Institute (ESRI), Redlands, CA.

F. X. Browne Inc., Tetra Tech Inc., RESOLVE Inc., and Fairfax County Stormwater Planning Division. (2011). "Nichol Run and Pond Branch Watershed Management plan.” Fairfax County, VA.

Fairfax County. (2015). "Watershed Management Plans.” Watersheds, Fairfax County, VA, $<$ https://www.fairfaxcounty.gov/dpwes/watersheds/>.

FB Environmental Associates. (2014). “Topsham Fair Mall Stream Watershed Based Plan.” Topsham, ME.

Fisher, R. A. (1970). "The exact treatment of 2x2 tables." Statistical Methods for Research Workers, E. A. Cornish, Darien, CT, 96-97.

Fletcher, T. D., Andrieu, H., and Hamel, P. (2013). "Understanding, Management and Modelling of Urban Hydrology and its Consequences for Receiving Waters: A State of the Art." Advances in Water Resources, 51, 261-279.

Galli, J. (1996). "Rapid Stream Assessment Technique (RSAT) Field Methods.” Metropolitan Washington Council of Governments, Washington D.C.

Glick, R. H. (2009). "Impacts of Impervious Cover and Other Factors on Storm-Water Quality in Austin, Tex." Journal of Hydrologic Engineering, 14(4), 316-323. 
Gregg, F., Rice, T., Kenney, D., and Mutz, K. (1998). "The State Role in Western Watershed Initiatives." Natural Resources Law Center, University of Colorado School of Law, Boulder, CO.

Heaney, J. P., Wright, L., and Sample, D. (2000). "Urban Stormwater and Watershed Management: A Case Study.” Innovative Urban Wet-Weather Flow Management Systems, R. Field, J. P. Heaney, and R. Pitt, eds., Technomic Publishing Co. Inc., Lancaster, PA, 329-389.

HydroCAD Software Solutions. (2011). "HydroCAD Stormwater Modeling System Version 10 Owner's Manual." Chocorua, NH.

IEPA. (2007). Guidance for Developing Watershed Action Plans in Illinois. Illinois

Environmental Protection Agency; Chicago Metropolitan Agency for Planning, Springfield, IL.

Jensen, M. E., Bourgeron, P., Everett, R., and Goodman, I. (1996). "Ecosystem Management: A Landscape Ecology Perspective." Journal of the American Water Resources Association (JAWRA), 32(2), 203-216.

St. John, D. (2005). "How Advances in GIS Improve Watershed Master Planning." Managing Watersheds for Human and Natural Impacts: Engineering, Ecological, and Economic Challenges, G. E. Moglen, ed., ASCE, Williamsburg, VA.

Johnson, M. L. (2005). "Using GIS For Stormwater Management and Responsible Land Use Planning." Managing Watersheds for Human and Natural Impacts.

Kaplan, J. K., and Watson, B. J. (2013). "Watershed Master Planning, City of Griffin, Georgia, USA.” Water Resources Management VII, WIT Press, 3-10.

Koski, K., and Lorenz, M. (1999). "Duck Creek Watershed Management Plan.” The Duck Creek Advisory Group, Juneau, AK.

Lake County. (2017). "Watershed Management Plans." Stormwater Management Commission,

Lake County, IL, <https://www.lakecountyil.gov/2437/Watershed-Management-Plans>. Lake County Stormwater Management Commission, and Northwater Consultants. (2014). "Mill Creek Watershed and Flood Mitigation Plan.” Lake County, IL.

Landers, J. (2010). "Entering the Mainstream.” Civil Engineering, 80(8), 58-69.

Lee, J. G., and Heaney, J. P. (2003). "Estimation of Urban Imperviousness and its Impacts on Storm Water Systems." Journal of Water Resources Planning and Management, 129(5), 
419-426.

Lee, J. G., Selvakumar, A., Alvi, K., Riverson, J., Zhen, J. X., Shoemaker, L., and Lai, F. (2012).

"A watershed-scale design optimization model for stormwater best management practices." Environmental Modelling and Software, 37, 6-18.

Leopold, L. B. (1968). Hydrology for Urban Land Planning - A Guidebook on the Hydrologic Effects of Urban Land Use. Geological Survey Circular, United States Department of the Interior, Washington D.C.

Maguire, L. A. (2003). "Interplay of Science and Stakeholder Values in Neuse River Total Maximum Daily Load Process." Journal of Water Resources Planning and Management, 129(4), 261-270.

McGarity, A. E. (2012). "Storm-Water Investment Strategy Evaluation Model for Impaired Urban Watersheds.” Journal of Water Resources Planning and Management, 138(2), 111124.

McGinnis, M. V. (1999). "Making the Watershed Connection.” Policy Studies Journal, 27(3), 497-501.

McGinnis, M. V., Woolley, J., and Gamman, J. (1999). "Bioregional Conflict Resolution: Rebuilding Community in Watershed Planning and Organizing." Environmental Management, 24(1), 1-12.

MEC Analytical Systems Inc. (2004). “Dominguez Watershed Management Master Plan.” County of Los Angeles Department of Public Works, Alhambra, CA.

Mirchi, A., Watkins, Jr., D., and Madani, K. (2010). "Modeling for Watershed Planning, Management, and Decision Making." Waatersheds: Management, Restoration and Environmental Impact (Environmental Science, Engineering and Technology), J. C.

Vaughn, ed., Nova Science Publishers Inc.

Montgomery County. (1997). "Lower Merion Drainage Area Act 167 Stormwater Management Plan." Montgomery County, PA.

NRC. (2004). Adaptive Management for Water Resources Project Planning. National Research Council, Washington D.C.

Olsson, J., Amaguchi, H., Alsterhag, E., Daverhog, M., Adrian, P.-E., and Kawamura, A. (2013).

"Adaptation to climate change impacts on urban storm water: a case study in Arvika, Sweden." Climatic Change, 116(2), 231-247. 
Ormsbee, L., and McAlister, M. (2014). "Evolution of a Watershed-Management Framework in the Kentucky River Basin.” Journal of Water Resource Planning and Management, 140(9), $1-11$.

Parsons. (2001). “Stevenson Creek Watershed Management Plan.” Clearwater, FL.

Philadelphia Water Department. (2005). “Tookany/Tacony-Creek Integrated Watershed Management Plan.” Tookany/Tacony-Frankford Watershed Partnership, Philadelphia, PA.

Pitt, R., Voorhees, J. G., Burger, C. L., and Joachim, D. (1997). "WinSLAMM Version 10.2 User's Guide.” PV \& Associates.

R Core Team. (2017). "R: A Language and Environment for Statistical Computing Version 3.4.2." R Foundation for Statistical Computing, Vienna, Austria. Retreived from https://www.r-project-org/.

Rollins, R. W., and Johnson, N. (2012). "Watkins Creek Watershed Management Plan.” Metropolitan St. Louis Sewer District, St. Louis, MO.

Romanova, A., Horoshenkov, K. V, Tait, S. J., and Ertl, T. (2013). "Sewer Inspections and Comparison of Acoustic and CCTV Methods." Water Management, 166(2), 70-80.

Rosgen, D. L. (2001). “A Practical Method of Computing Streambank Erosion Rate.” Proceedings of the Seventh Federal Interagency Sedimentation Conference, Reno, NV, 915.

Rossman, L. A. (2015). “Storm Water Management Model (SWMM) User's Manual Version 5.1.” U.S. Environmental Protection Agency, Cincinnati, OH.

Rubin, Z., Kondolf, G. M., and Rios-Touma, B. (2017). "Evaluating Stream Restoration Projects: What Do We Learn from Monitoring?” Water, 9(3), 174-189.

Ruhl, J. B. (1999). "The (Political) Science of Watershed Management in the Ecosystem Age." Journal of the American Water Resources Association, 35(3), 519-526.

Rutgers Cooperative Extension Water Resources Program. (2013). "Tenakill Brook Watershed Restoration and Protection Plan.” Bergen County, NJ.

Salvadore, E., Bronders, J., and Batelaan, O. (2015). "Hydrological Modelling of Urbanized Catchments: A Review and Future Directions.” Journal of Hydrology, 529, 62-81.

Schueler, T. (1987). Controlling Urban Runoff: A Practical Manual for Planning and Designing Urban BMPs. Metropolitan Washington Council of Governments, Washington D.C.

Schueler, T. R. (1996). “Crafting Better Urban Watershed Protection Plans.” Watershed 
Protection Techniques, 2(2), 329-337.

Semadeni-Davies, A., Hernebring, C., Svensson, G., and Gustafsson, L.-G. (2008). “The impacts of climate change and urbanisation on drainage in Helsingborg, Sweden: Suburban stormwater." Journal of Hydrology, 350(1-2), 114-125.

Seth, I., Soonthornnonda, P., and Christensen, E. R. (2006). "Use of GIS in Urban Storm-Water Modeling." Journal of Environmental Engineering, 132(12), 1550-1553.

Shilling, F., Sommarstrom, S., Kattelmann, R., Florsheim, J., Henly, R., and Washburn, B. (2005). "The California Watershed Assessment Manual: Volume I."

Soil Conservation Service. (1992). "TR-20 Computer Program for Project Formulation Hydrology.” Soil Conservation Service Hydrology Unit and Technology Development Support Staff.

Somerville, D. E., and Pruitt, B. A. (2004). "Physical Stream Assessment: A Review of Selected Protocols for Use in the Clean Water Act Section 404 Program." U.S. Environmental Protection Agency, Office of Wetlands, Oceans, and Watersheds, Wetlands Division, Washington D.C.

Streamline Technologies Inc. (2016). "Interconnected Channel and Pond Routing Model (ICPR) Version 4.” Available from http://www.streamnologies.com/, Winter Springs, FL.

Strecker, E. W., Quigley, M. M., Urbonas, B. R., Jones, J. E., and Clary, J. K. (2001). "Determining Urban Storm Water BMP Effectiveness." Journal of Water Resources Planning and Management, 127(3), 144-149.

Talebi, L., Kuczynski, A., Graettinger, A. J., and Pitt, R. (2014). “Automated Classification of Urban Areas for Storm Water Management Using Aerial Photography and LiDAR." Journal of Hydrologic Engineering, 19(5), 887-895.

Teng, J., Jakeman, A. J., Vaze, J., Croke, B. F. W., Dutta, D., and Kim, S. (2017). “Flood Inundation Modelling: A Review of Methods, Recent Advances and Uncertainty Analysis." Environmental Modelling and Software, 90, 201-216.

Terstriep, M. L., and Stall, J. B. (1974). “The Illinois Urban Drainage Area Simulator; ILLUDAS.” Illinois State Water Survey, Urbana, IL.

Tetra Tech Inc. (2009). "Loading Simulation Program in C++ (LSPC) Version 3.1 User's Manual." Fairfax, VA.

Tetra Tech Inc. (2017). “User’s Guide: Spreadsheet Tool for the Estimation of Pollutant Load 
(STEPL) Version 4.4.” U.S. Environmental Protection Agency, Fairfax, VA.

The Louis Berger Group Inc., Gannett Fleming Inc., and City of Fairfax. (2005). "City of

Fairfax, Virginia Watershed Management Plan.” City of Fairfax, Fairfax, VA.

U.S. Army Corps of Engineers. (1998). “HEC-1 Flood Hydrograph Package User's Manual

Version 4.1.” U.S. Army Corps of Engineers Hydrologic Engineering Center, Davis, CA.

U.S. Army Corps of Engineers. (2016a). “HEC-RAS River Analysis System User's Manual

Version 5.0.” U.S. Army Corps of Engineers Hydrologic Engineering Center, Davis, CA.

U.S. Army Corps of Engineers. (2016b). "Hydrologic Modeling System HEC-HMS User's

Manual Version 4.2." U.S. Army Corps of Engineers Hydrologic Engineering Center,

Davis, CA.

University of Arkansas Community Design Center, Fay Jones School of Architecture + Design,

University of Arkansas Department of Biological and Agricultural Engineering, Arkansas

Natural Resources Commission, and City of Conway. (2016). "Conway Urban Watershed

Framework Plan.” Conway, AR.

USDA. (1998). "Stream Visual Assessment Protocol.” National Water and Climate Center

Technical Note 99-1, U.S. Department of Agriculture, Natural Resources Conservation

Service.

USDA-ARS, EPA, and University of Wyoming. (2015). “Automated Geospatial Watershed

Assessment (AGWA) Version 3.” U.S. Department of Agriculture Southwest Watershed

Research Center, Tucson, AZ.

Wagner, W. E. (2006). "Stormy Regulation: The Problems that Result when Stormwater (and

Other) Regulatory Programs Neglect to Account for Limitations in Scientific and Technical Information." Chapman Law Review, 9(2), 191-231.

Walsh, C. J., Booth, D. B., Burns, M. J., Fletcher, T. D., Hale, R. L., Hoang, L. N., Livingston, G., Rippy, M. A., Roy, A. H., Scoggins, M., and Wallace, A. (2016). "Principles for urban stormwater management to protect stream ecosystems." Journal of Freshwater Science, 35(1), 398-411.

Walsh, C. J., Roy, A. H., Feminella, J. W., Cottingham, P. D., Groffman, P. M., and Morgan, R. P. I. (2005). "The Urban Stream Syndrome: Current Knowledge and the Search for a Cure." Journal of the North American Benthological Society, 24(3), 706-723.

Wang, G., Mang, S., Cai, H., Liu, S., Zhang, Z., Wang, L., and Innes, J. L. (2016). “Integrated 
Watershed Management: Evolution, Development, and Emerging Trends." Journal of Forestry Research, Springer Berlin Heidelberg, 27(5), 967-994.

Wang, Y., Montas, H. J., Brubaker, K. L., Leisnham, P. T., Shirmohammadi, A., Chanse, V., and Rockler, A. K. (2017). “A Diagnostic Decision Support System for BMP Selection in Small Urban Watershed." Water Resources Management, 31(5), 1649-1664.

Western Water Policy Review Advisory Commission. (1998). Water in the West: The Challenge for the Next Century. Albuquerque, NM.

Whipple, W., Grigg, N. S., Grizzard, T., Randall, C. W., Schubinski, R. P., and Tucker, L. S. (1983). Stormwater Management in Urbanizing Areas. Prentice-Hall Inc., Englewood Cliffs, NJ.

Whiteaker, T. L., Maidment, D. R., Goodall, J. L., and Takamatsu, M. (2006). "Integrating Arc Hydro Features with a Schematic Network." Transactions in GIS, 10(2), 219-237.

Willems, P., Arnbjerg-Nielsen, K., Olsson, J., and Nguyen, V. T. V. (2012). "Climate Change Impact Assessment on Urban Rainfall Extremes and Urban Drainage: Methods and Shortcomings." Atmospheric Research, 103, 106-118.

Wurbs, R. A. (1994). Computer Models for Water Resources Planning and Management. Institute for Water Resources. 


\section{APPENDIX A - LIST OF 63 STUDY WMPS}

\begin{tabular}{|c|c|c|c|c|c|c|}
\hline Number & State & Location & Plan Name & Year & Author & URL \\
\hline 1 & AK & Juneau & $\begin{array}{l}\text { Duck Creek Watershed } \\
\text { Management Plan }\end{array}$ & 1999 & Koski, K. and Lorenz, M. & $\begin{array}{l}\text { https://dec.alaska.gov/water/wnpspc/protection } \\
\text { restoration/juneau/pdfs/1999_Duck_Creek_W } \\
\text { atershed_Management_Plan.pdf }\end{array}$ \\
\hline 2 & AK & Anchorage & $\begin{array}{l}\text { Little Campbell Creek Watershed } \\
\text { Management Plan }\end{array}$ & 2007 & $\begin{array}{l}\text { Anchorage Municipal } \\
\text { Watershed Management } \\
\text { Services } \\
\end{array}$ & $\begin{array}{l}\text { http://anchoragestormwater.com/Documents/Fi } \\
\text { nal\%20LCC\%20WMP-3.pdf }\end{array}$ \\
\hline 3 & AK & Anchorage & Chester Creek Watershed Plan & 2005 & HDR Alaska Inc. & $\begin{array}{l}\text { http://anchoragecreeks.org/media/publications/ } \\
\text { Chester\%20Creek\%20Watershed\%20plan.pdf }\end{array}$ \\
\hline 4 & $\mathrm{AK}$ & Anchorage & Chester Creek Watershed Plan & 2014 & Anchorage Waterways Council & $\begin{array}{l}\text { http://anchoragestormwater.com/Documents/C } \\
\text { hester\%20Watershed\%20Plan\%20Draft } \% 203 \\
\% 209-27-14 . \text { pdf }\end{array}$ \\
\hline 5 & AK & Anchorage & $\begin{array}{l}\text { Pilot Watershed Drainage Plan: } \\
\text { Little Rabbit Creek and Little } \\
\text { Survival Creek Watersheds } \\
\end{array}$ & 2008 & $\begin{array}{l}\text { HDR Alaska Inc. and } \\
\text { WHPacific Inc. }\end{array}$ & $\begin{array}{l}\text { http://anchoragestormwater.com/Documents/lit } \\
\text { tle_rabbit-little_survival_pilot_plan_12-08.pdf }\end{array}$ \\
\hline 6 & $\mathrm{AL}$ & Cullman County & $\begin{array}{l}\text { Watershed Plan and Environmental } \\
\text { Impact Statement for Watershed } \\
\text { Protection and Flood Prevention: } \\
\text { Mud Creek }\end{array}$ & 1976 & Cullman County Commission & $\begin{array}{l}\text { https://www.archive.org/stream/CAT76673529 } \\
\text { ?ref=ol\#page/n3/mode/2up }\end{array}$ \\
\hline 7 & $\mathrm{AL}$ & (mixed) & $\begin{array}{l}\text { Mill Creek Watershed } \\
\text { Management Plan }\end{array}$ & 2010 & ALOA & $\begin{array}{l}\text { http://www.aces.edu/natural-resources/water- } \\
\text { resources/watershed-planning/watershed- } \\
\text { projects/millcreek/documents/MCWMP_Final } \\
\text { 12.17.10_reduced_size.pdf }\end{array}$ \\
\hline 8 & $\mathrm{AL}$ & (mixed) & $\begin{array}{l}\text { Parkerson Mill Creek Watershed } \\
\text { Management Plan }\end{array}$ & 2011 & ALOA & $\begin{array}{l}\text { http://www.aces.edu/natural-resources/water- } \\
\text { resources/watershed-planning/watershed- } \\
\text { projects/parkersonmillcreek/documents/PMCP } \\
\text { LAN_LR.pdf }\end{array}$ \\
\hline 9 & $\mathrm{AZ}$ & Prescott & $\begin{array}{l}\text { Improvement Plan for the Upper } \\
\text { Granite Creek Watershed, Arizona }\end{array}$ & 2012 & $\begin{array}{l}\text { Watershed Improvement } \\
\text { Council }\end{array}$ & $\begin{array}{l}\text { https://legacy.azdeq.gov/environ/water/watersh } \\
\text { ed/download/gc_wip.pdf }\end{array}$ \\
\hline 10 & $\mathrm{CA}$ & Los Angeles County & $\begin{array}{l}\text { Dominguez Watershed } \\
\text { Management Master Plan }\end{array}$ & 2004 & MEC Analytical Systems Inc. & $\begin{array}{l}\text { https://dpw.lacounty.gov/wmd/watershed/dc/D } \\
\text { CMP/masterplan.cfm }\end{array}$ \\
\hline 11 & $\mathrm{CA}$ & Berkeley & Watershed Management Plan & 2011 & $\begin{array}{l}\text { City of Berkeley Public Works } \\
\text { Engineering }\end{array}$ & $\begin{array}{l}\text { https://www.cityofberkeley.info/Public_Works } \\
\text { /Sewers_- } \\
\text { Storm/Watershed_Management_Plan.aspx }\end{array}$ \\
\hline 12 & $\mathrm{CA}$ & Santa Monica & $\begin{array}{l}\text { City of Santa Monica Watershed } \\
\text { Management Plan }\end{array}$ & 2006 & Brown and Caldwell & $\begin{array}{l}\text { https://www.smgov.net/Departments/OSE/Cate } \\
\text { gories/Urban_Runoff/Watershed_Management } \\
\text { Plan.aspx }\end{array}$ \\
\hline
\end{tabular}




\begin{tabular}{|c|c|c|c|c|c|c|}
\hline 13 & $\mathrm{CA}$ & Oakland & East Bay Watershed Master Plan & 1996 & Jones \& Stokes Associates Inc. & $\begin{array}{l}\text { https://www.ebmud.com/index.php/download_ } \\
\text { file/force/1010/189/?EBMUD_Watershed_Ma } \\
\text { ster_Plan_3.pdf }\end{array}$ \\
\hline 14 & $\mathrm{CA}$ & Oakland & East Bay Watershed Master Plan & 2016 & $\begin{array}{l}\text { East Bay Municipal Utility } \\
\text { District }\end{array}$ & $\begin{array}{l}\text { http://www.ebmud.com/recreation/east- } \\
\text { bay/east-bay-watershed-master-plan-update/ }\end{array}$ \\
\hline 15 & $\mathrm{CT}$ & (mixed) & $\begin{array}{l}\text { North Branch Park River } \\
\text { Watershed Management Plan }\end{array}$ & 2010 & Fuss \& O'Neill & $\begin{array}{l}\text { http://www.ct.gov/deep/lib/deep/water/watersh } \\
\text { ed_management/wm_plans/nbparkr/nbpr_wbp. } \\
\text { pdf }\end{array}$ \\
\hline 16 & $\mathrm{CT}$ & (mixed) & $\begin{array}{l}\text { Mianus River Watershed Based } \\
\text { Plan }\end{array}$ & 2012 & AKRF Inc. & $\begin{array}{l}\text { http://www.mianus.org/wp- } \\
\text { content/uploads/2016/04/Mianus_Plan_Final_ } \\
\text { Reduced.pdf }\end{array}$ \\
\hline 17 & $\mathrm{DC}$ & Washington D.C. & $\begin{array}{l}\text { Anacostia River Watershed } \\
\text { Implementation Plan }\end{array}$ & 2012 & $\begin{array}{l}\text { District Department of the } \\
\text { Environment }\end{array}$ & $\begin{array}{l}\text { https://doee.dc.gov/sites/default/files/dc/sites/d } \\
\text { doe/publication/attachments/Anacostia_WIP_2 } \\
\text { 012_Final.pdf }\end{array}$ \\
\hline 18 & FL & Clearwater & $\begin{array}{l}\text { Stevenson Creek Watershed } \\
\text { Management Plan }\end{array}$ & 2001 & Parsons ES & $\begin{array}{l}\text { http://legacy.myclearwater.com/gov/depts/pwa } \\
\text { /engin/publications/watersheds/StevensonCree } \\
\text { k/index.asp }\end{array}$ \\
\hline 19 & FL & Clearwater & $\begin{array}{l}\text { Alligator Creek Watershed } \\
\text { Management Plan }\end{array}$ & 2011 & Interflow Engineering LLC & $\begin{array}{l}\text { http://legacy.myclearwater.com/gov/depts/pwa } \\
\text { /engin/StormwaterMgt/AlligatorCreek/reports/ } \\
\text { WatershedEvalReportFINAL.pdf }\end{array}$ \\
\hline 20 & GA & Villa Rica & $\begin{array}{l}\text { City of Villa Rica, Georgia } \\
\text { Watershed Protection Plan }\end{array}$ & 2010 & $\begin{array}{l}\text { Brennan Jones Engineering } \\
\text { Associates LLC }\end{array}$ & $\begin{array}{l}\text { http://villarica.org/files/documents/WatershedP } \\
\text { rotectionPlan1324111624011116AM.pdf }\end{array}$ \\
\hline 21 & GA & Atlanta & $\begin{array}{l}\text { Peachtree Creek Watershed } \\
\text { Improvement Plan }\end{array}$ & 2017 & $\mathrm{BC} / \mathrm{DHA}$ & $\begin{array}{l}\text { http://www.atlantawatershed.org/inside- } \\
\text { dwm/offices/watershed-protection/atlantas- } \\
\text { watersheds/peachtree-creek-watershed/ }\end{array}$ \\
\hline 22 & GA & Atlanta & $\begin{array}{l}\text { South River Watershed } \\
\text { Improvement Plan }\end{array}$ & 2010 & Arcadis Inc. & $\begin{array}{l}\text { http://www.atlantawatershed.org/inside- } \\
\text { dwm/offices/watershed-protection/atlantas- } \\
\text { watersheds/south-river-watershed/ }\end{array}$ \\
\hline 23 & GA & Griffin & $\begin{array}{l}\text { Cabin Creek Watershed Protection } \\
\text { Plan }\end{array}$ & 2012 & Tetra Tech Inc. & $\begin{array}{l}\text { http://www.cityofgriffin.com/portals/1/docume } \\
\text { nts/stormwater/watershed\%20management/Pro } \\
\text { tection\%20plans/Cabin\%20Creek\%20Protectio } \\
\text { n\%20Plan\%20v6.pdf }\end{array}$ \\
\hline 24 & $\mathrm{HI}$ & Maui County & $\begin{array}{l}\text { Watershed Plan and Environmental } \\
\text { Assessment: Lahaina Watershed }\end{array}$ & 1992 & County of Maui and USDA & $\begin{array}{l}\text { https://www.nrcs.usda.gov/Internet/FSE_DOC } \\
\text { UMENTS/nrcs142p2_036789.pdf }\end{array}$ \\
\hline 25 & IA & Cedar Falls & $\begin{array}{l}\text { Watershed Management Plan for } \\
\text { Dry Run Creek Watershed }\end{array}$ & 2009 & Black Hawk Soil District & $\begin{array}{l}\text { http://www.iowadnr.gov/portals/idnr/uploads/ } \\
\text { water/watershed/files/dryruncreekwmp.pdf?am } \\
\text { p;tabid=771 }\end{array}$ \\
\hline 26 & IL & Lake County & $\begin{array}{l}\text { Mill Creek Watershed and Flood } \\
\text { Mitigation Plan }\end{array}$ & 2014 & $\begin{array}{l}\text { Lake County Stormwater } \\
\text { Management Commission }\end{array}$ & $\begin{array}{l}\text { http://www.epa.illinois.gov/Assets/iepa/water- } \\
\text { quality/watershed-management/watershed- } \\
\text { based-planning/2016/mill-cr.pdf }\end{array}$ \\
\hline 27 & IL & Lake County & $\begin{array}{l}\text { Indian Creek Watershed-Based } \\
\text { Plan }\end{array}$ & 2006 & $\begin{array}{l}\text { Lake County Stormwater } \\
\text { Management Commission }\end{array}$ & $\begin{array}{l}\text { https://www.lakecountyil.gov/DocumentCenter } \\
\text { /View/11363 }\end{array}$ \\
\hline
\end{tabular}




\begin{tabular}{|c|c|c|c|c|c|c|}
\hline 28 & MA & Franklin & $\begin{array}{l}\text { Stormwater Management Plan for } \\
\text { Spruce Pond Brook Subwatershed }\end{array}$ & 2011 & $\begin{array}{l}\text { Charles River Watershed } \\
\text { Association }\end{array}$ & $\begin{array}{l}\text { http://www.crwa.org/hs-fs/hub/311892/file- } \\
\text { 636820515- } \\
\text { pdf/Our_Work_/Blue_Cities_Initiative/Scientif } \\
\text { ic_and_Technical/CRWA_Franklin_Plan.pdf }\end{array}$ \\
\hline 29 & MD & Gaithersburg & Muddy Branch Watershed Study & 2014 & URS Corporation & $\begin{array}{l}\text { http://www.gaithersburgmd.gov/ /media/city/d } \\
\text { ocuments/services/environmental/muddy_bran } \\
\text { ch_watershed_study.pdf }\end{array}$ \\
\hline 30 & $\mathrm{MD}$ & (mixed) & $\begin{array}{l}\text { Plumtree Run Watershed Small } \\
\text { Watershed Action Plan }\end{array}$ & 2011 & BayLand Consultants & $\begin{array}{l}\text { https://www.belairmd.org/DocumentCenter/Vi } \\
\text { ew/923 }\end{array}$ \\
\hline 31 & MD & Baltimore County & $\begin{array}{l}\text { Upper Back River Small } \\
\text { Watershed Action Plan }\end{array}$ & 2008 & Baltimore County & $\begin{array}{l}\text { https://www.baltimorecountymd.gov/Agencies } \\
\text { /environment/watersheds/backmain.html }\end{array}$ \\
\hline 32 & MD & $\begin{array}{l}\text { Anne Arundel } \\
\text { County }\end{array}$ & $\begin{array}{l}\text { Severn River Watershed } \\
\text { Management Master Plan }\end{array}$ & 2006 & KCI Technologies Inc. & $\begin{array}{l}\text { http://www.aacounty.org/departments/public- } \\
\text { works/wprp/forms-and- } \\
\text { publications/Severn_Final_Report_2-2006.pdf }\end{array}$ \\
\hline 33 & MD & Rockville & $\begin{array}{l}\text { Watts Branch Watershed Study and } \\
\text { Management Plan Final Report }\end{array}$ & 2001 & $\begin{array}{l}\text { Center for Watershed } \\
\text { Protection, Macris Hendricks } \\
\text { and Glasock Inc., and } \\
\text { Environmental Systems } \\
\text { Analysis Inc. }\end{array}$ & $\begin{array}{l}\text { http://www.rockvillemd.gov/DocumentCenter/ } \\
\text { View/1751 }\end{array}$ \\
\hline 34 & $\mathrm{ME}$ & Topsham & $\begin{array}{l}\text { Topsham Fair Mall Stream } \\
\text { Watershed Based Plan }\end{array}$ & 2014 & FB Environmental Associates & $\begin{array}{l}\text { http://www.topshammaine.com/vertical/sites/ } \\
\text { \%7B95A28B10-4485-4BEC-B8FC- } \\
\text { 5E8BF056A147\%7D/uploads/Topsham_WBP } \\
\text { 4April2014__FINAL_PLAN.pdf }\end{array}$ \\
\hline 35 & $\mathrm{ME}$ & Saco & Goosefare Brook Watershed & 2016 & FB Environmental Associates & $\begin{array}{l}\text { http://www.sacomaine.org/departments/public } \\
\text { _works/goosefarebrookwatershed.php }\end{array}$ \\
\hline 36 & MI & Ann Arbor & $\begin{array}{l}\text { Millers Creek Watershed } \\
\text { Improvement Plan }\end{array}$ & 2004 & $\begin{array}{l}\text { Ayres, Lewis, Norris, \& May } \\
\text { Inc., Huron River Watershed } \\
\text { Council, and Tilton and } \\
\text { Associates Inc. }\end{array}$ & $\begin{array}{l}\text { http://www.michigan.gov/documents/deq/ess- } \\
\text { nps-wmp-millers-creek-part1_210568_7.pdf }\end{array}$ \\
\hline 37 & MO & St. Louis County & $\begin{array}{l}\text { Watkins Creek Watershed } \\
\text { Management Plan }\end{array}$ & 2012 & $\begin{array}{l}\text { St. Louis Metropolitan Sewer } \\
\text { District }\end{array}$ & $\begin{array}{l}\text { https://dnr.mo.gov/env/swcp/nps/mgmtplan/do } \\
\text { cs/20120924-watkins-cr-wmp.pdf }\end{array}$ \\
\hline 38 & MO & St. Peters & $\begin{array}{l}\text { Nine Critical Element Plan for the } \\
\text { Spencer Creek Watershed }\end{array}$ & 2012 & Black \& Veatch & $\begin{array}{l}\text { https://www.stpetersmo.net/Water/NineCritical } \\
\text { ElementPlan-SpencerCrkWtrshd.pdf }\end{array}$ \\
\hline 39 & $\mathrm{NC}$ & Greenville & $\begin{array}{l}\text { Greens Mill Run Watershed Master } \\
\text { Plan }\end{array}$ & 2016 & Hazen and Sawyer & $\begin{array}{l}\text { http://www.greenvillenc.gov/government/publi } \\
\text { c-works/watershed-master-plans }\end{array}$ \\
\hline 40 & $\mathrm{NC}$ & Durham & $\begin{array}{l}\text { Little Lick Creek Watershed } \\
\text { Improvement Plan }\end{array}$ & 2016 & Wildlands Engineering & $\begin{array}{l}\text { https://durhamnc.gov/960/Little-Lick-Creek- } \\
\text { Watershed-Plan }\end{array}$ \\
\hline 41 & NE & Lincoln & $\begin{array}{l}\text { Antelope Creek Watershed Basin } \\
\text { Management Plan }\end{array}$ & 2012 & $\begin{array}{l}\text { EA Engineering, Science, and } \\
\text { Technology }\end{array}$ & $\begin{array}{l}\text { http://lincoln.ne.gov/city/pworks/watershed/ma } \\
\text { ster-plan/antelope-creek/ }\end{array}$ \\
\hline 42 & $\mathrm{NE}$ & Lincoln & $\begin{array}{l}\text { Beal Slough Stormwater Master } \\
\text { Plan }\end{array}$ & 2000 & $\begin{array}{l}\text { Olsson Associates and Wright } \\
\text { Water Engineers }\end{array}$ & $\begin{array}{l}\text { http://lincoln.ne.gov/city/pworks/watershed/ma } \\
\text { ster-plan/beal-slough/ }\end{array}$ \\
\hline 43 & $\mathrm{NE}$ & Lincoln & $\begin{array}{l}\text { Deadmans Run Watershed Master } \\
\text { Plan }\end{array}$ & 2007 & $\mathrm{CDM}$ & $\begin{array}{l}\text { http://lincoln.ne.gov/city/pworks/watershed/ma } \\
\text { ster-plan/deadmans-run/ }\end{array}$ \\
\hline
\end{tabular}




\begin{tabular}{|c|c|c|c|c|c|c|}
\hline 44 & $\mathrm{NE}$ & Lincoln & $\begin{array}{l}\text { Middle Creek Watershed Master } \\
\text { Plan Study }\end{array}$ & 2015 & Intuition \& Logic & $\begin{array}{l}\text { http://lincoln.ne.gov/city/pworks/watershed/ma } \\
\text { ster-plan/middle-creek/ }\end{array}$ \\
\hline 45 & NJ & Bergen County & $\begin{array}{l}\text { Tenakill Brook Watershed } \\
\text { Restoration \& Protection Plan }\end{array}$ & 2013 & $\begin{array}{l}\text { Rutgers Cooperative Extension } \\
\text { Water Resources Program }\end{array}$ & $\begin{array}{l}\text { http://www.nj.gov/dep/wms/bears/docs/FINAL } \\
\% 20 \& \% 20 \text { Complete_Tenakill_Brook_Restorat } \\
\text { ion_Plan_01222013.pdf }\end{array}$ \\
\hline 46 & $\mathrm{OH}$ & Cincinnati & Lick Run Watershed Master Plan & 2012 & $\begin{array}{l}\text { Metropolitan Sewer District of } \\
\text { Greater Cincinnati }\end{array}$ & $\begin{array}{l}\text { http://www.projectgroundwork.org/downloads/ } \\
\text { lickrun/lick_run_master_plan.pdf }\end{array}$ \\
\hline 47 & $\mathrm{OH}$ & Cleveland & $\begin{array}{l}\text { Doan Brook Watershed Action } \\
\text { Plan }\end{array}$ & 2013 & $\begin{array}{l}\text { Doan Brook Watershed } \\
\text { Partnership }\end{array}$ & $\begin{array}{l}\text { http://www.doanbrookpartnership.org/resource } \\
\text { s/doan-brook-watershed-action-plan-1 }\end{array}$ \\
\hline 48 & OR & Clackamas County & $\begin{array}{l}\text { Watershed Action Plan: Kellogg- } \\
\text { Mt. Scott Watershed }\end{array}$ & 2009 & Brown and Caldwell & $\begin{array}{l}\text { http://www.clackamas.us/wes/documents/kello } \\
\text { gmtscottactionplan.pdf }\end{array}$ \\
\hline 49 & PA & Philadelphia & $\begin{array}{l}\text { Tookany/Tacony-Creek Integrated } \\
\text { Watershed Management Plan }\end{array}$ & 2005 & $\begin{array}{l}\text { Doan Brook Watershed } \\
\text { Partnership }\end{array}$ & $\begin{array}{l}\text { http://www.phillywatersheds.org/doc/Tacony_ } \\
\text { Frankford_WMP.pdf }\end{array}$ \\
\hline 50 & PA & Montgomery County & $\begin{array}{l}\text { Stony Creek/Saw Mill Run Act } \\
167 \text { Stormwater Management Plan }\end{array}$ & 1991 & $\begin{array}{l}\text { Montgomery County Planning } \\
\text { Commission }\end{array}$ & $\begin{array}{l}\text { https://www.montcopa.org/DocumentCenter/V } \\
\text { iew/6583 }\end{array}$ \\
\hline 51 & PA & Montgomery County & $\begin{array}{l}\text { Lower Merion Drainage Area Act } \\
167 \text { Stormwater Management Plan }\end{array}$ & 1997 & $\begin{array}{l}\text { Montgomery County Planning } \\
\text { Commission }\end{array}$ & $\begin{array}{l}\text { https://www.montcopa.org/DocumentCenter/V } \\
\text { iew/6578 }\end{array}$ \\
\hline 52 & PA & Chester County & $\begin{array}{l}\text { Valley Creek Watershed } \\
\text { Stormwater Management Plan }\end{array}$ & 2010 & $\begin{array}{l}\text { Chester County Water } \\
\text { Resources Authority and } \\
\text { Borton-Lawson Engineering } \\
\text { Inc. }\end{array}$ & $\begin{array}{l}\text { http://www.chesco.org/DocumentCenter/View/ } \\
6824\end{array}$ \\
\hline 53 & $\mathrm{TX}$ & Austin & Watershed Protection Master Plan & 2001 & City of Austin & $\begin{array}{l}\text { http://www.austintexas.gov/department/waters } \\
\text { hed-protection-master-plan }\end{array}$ \\
\hline 54 & $\mathrm{TX}$ & Austin & Watershed Protection Master Plan & 2016 & City of Austin & $\begin{array}{l}\text { http://www.austintexas.gov/watershed_protecti } \\
\text { on/publications/document.cfm?id=261630 }\end{array}$ \\
\hline 55 & VA & Falls Church & Watershed Management Plan & 2012 & AMEC Inc. & $\begin{array}{l}\text { https://www.fallschurchva.gov/DocumentCent } \\
\text { er/View/771 }\end{array}$ \\
\hline 56 & VA & Reston & Reston, Virginia Watershed Plan & 2002 & GKY and Associates Inc. & $\begin{array}{l}\text { https://www.reston.org/Parks,RecreationEvent } \\
\text { s/Watershed/WatershedMasterplan/tabid/602/ } \\
\text { Default.aspx }\end{array}$ \\
\hline 57 & VA & Fairfax County & $\begin{array}{l}\text { Little Hunting Creek Watershed } \\
\text { Management Plan }\end{array}$ & 2004 & Woolpert LLP & $\begin{array}{l}\text { https://www.fairfaxcounty.gov/dpwes/watershe } \\
\text { ds/littlehuntingcreek.htm }\end{array}$ \\
\hline 58 & VA & Fairfax County & $\begin{array}{l}\text { Cameron Run Watershed } \\
\text { Management Plan }\end{array}$ & 2007 & Versar Inc. & $\begin{array}{l}\text { https://www.fairfaxcounty.gov/dpwes/watershe } \\
\text { ds/cameronrun.htm }\end{array}$ \\
\hline 59 & VA & Fairfax County & $\begin{array}{l}\text { Nichol Run and Pond Branch } \\
\text { Watershed Management Plan }\end{array}$ & 2011 & F. X. Browne Inc. & $\begin{array}{l}\text { https://www.fairfaxcounty.gov/dpwes/watershe } \\
\text { ds/nicholrun.htm }\end{array}$ \\
\hline 60 & VA & Loudoun County & $\begin{array}{l}\text { Upper Broad Run Watershed } \\
\text { Management Plan }\end{array}$ & 2014 & Versar Inc. & $\begin{array}{l}\text { https://www.loudoun.gov/upperbroadrunwaters } \\
\text { hed }\end{array}$ \\
\hline 61 & VA & Fairfax & $\begin{array}{l}\text { City of Fairfax, Virginia } \\
\text { Watershed Management Plan }\end{array}$ & 2005 & Louis Berger Group & $\begin{array}{l}\text { http://www.fairfaxva.gov/home/showdocument } \\
\text { ?id=386 }\end{array}$ \\
\hline
\end{tabular}




\begin{tabular}{|c|c|c|c|c|c|c|}
\hline 62 & WA & Bellingham & Watershed Master Plan & 1995 & $\begin{array}{l}\text { David Evans and Associates } \\
\text { Inc. and HDR Engineering Inc. }\end{array}$ & $\begin{array}{l}\text { https://www.cob.org/documents/pw/storm/199 } \\
\text { 5-watershed-master-plan.pdf }\end{array}$ \\
\hline 63 & WA & (mixed) & Paradise Creek Watershed Plan & 1997 & Palouse Conservation District & $\begin{array}{l}\text { http://digital.lib.uidaho.edu/utils/getfile/collecti } \\
\text { on/idahowater/id/326/filename/326.pdf\#toolba } \\
\text { r=1\&navpanes=1 }\end{array}$ \\
\hline
\end{tabular}




\section{APPENDIX B - TEMPLATE FOR QUALITATIVE REVIEW}

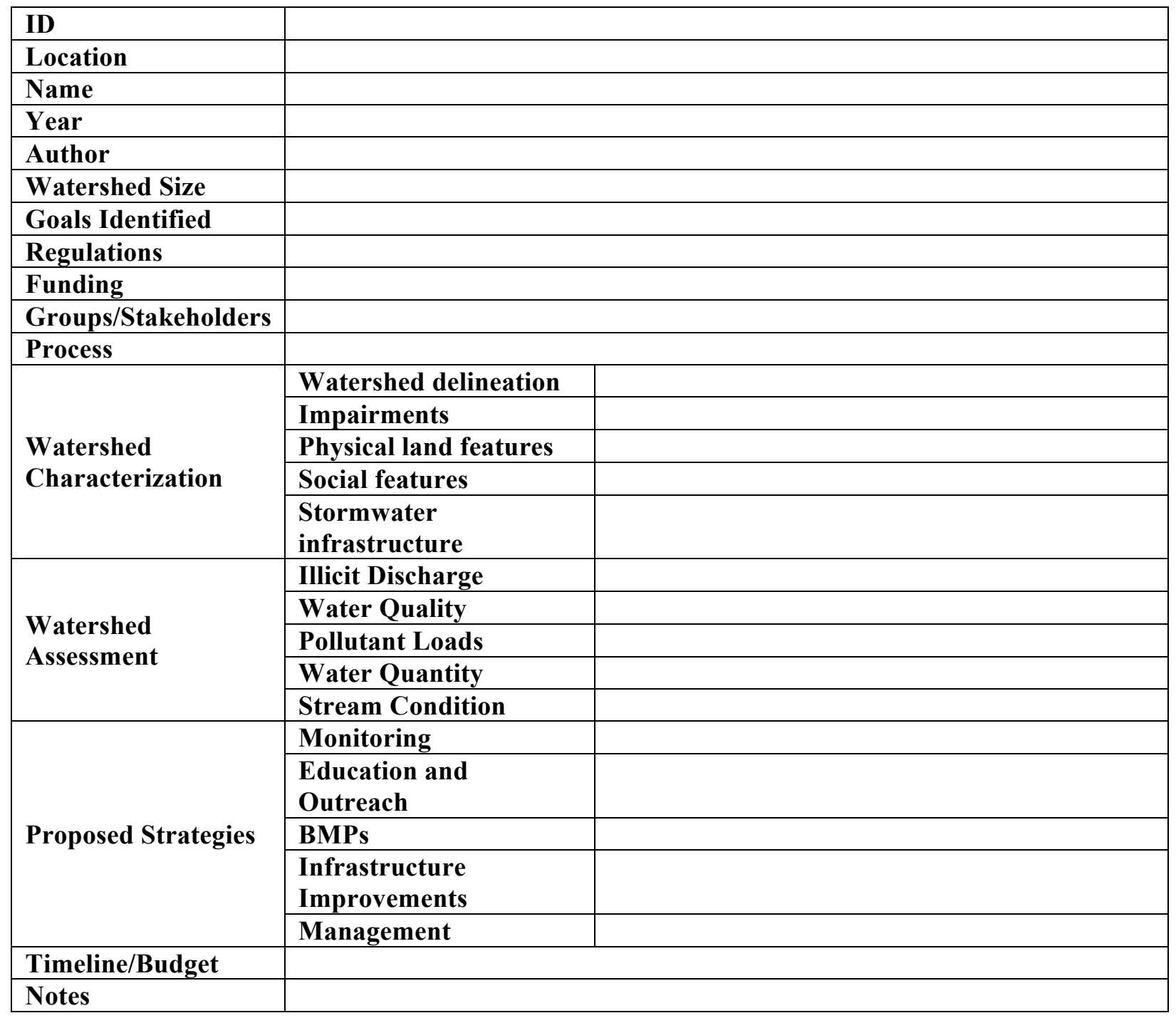




\section{APPENDix C - SAMPle OF StUdy Database (N=124)}

This table is a sample of the study database for the 124 WMPs within the scope of the study. The 63 WMPs reviewed are indicated by a number. "1" refers to "Yes" and "0" refers to "No" where applicable.

\begin{tabular}{|c|c|c|c|c|c|c|c|c|c|c|c|c|c|c|c|c|c|c|c|c|c|c|}
\hline \# & 田 & 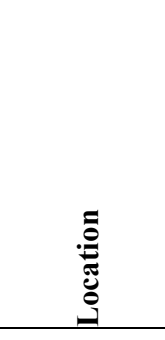 & $\begin{array}{c}\stackrel{\Xi}{\Xi} \\
\text { Ż } \\
\end{array}$ & $\stackrel{\bar{\nu}}{\bar{\nu}}$ & 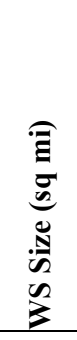 & 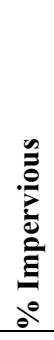 & 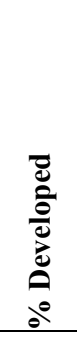 & 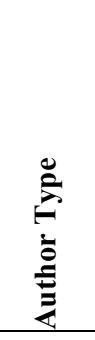 & 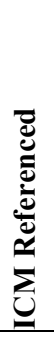 & $\sum_{\Sigma}^{+\infty}$ & 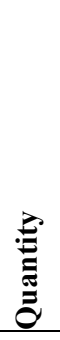 & 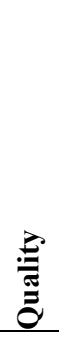 & 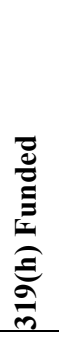 & 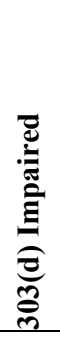 & 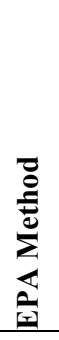 & 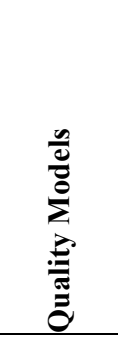 & 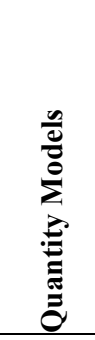 & 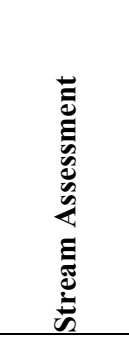 & 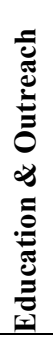 & 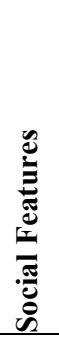 & 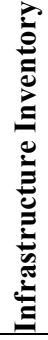 & 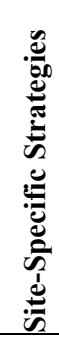 \\
\hline 1 & AK001 & Juneau & $\begin{array}{l}\text { Duck Creek Watershed } \\
\text { Management Plan }\end{array}$ & 1999 & 1.7 & 36 & -- & AGY & 0 & 0 & 1 & 1 & 1 & 1 & 0 & -- & -- & -- & 1 & 1 & 0 & 0 \\
\hline 2 & AK002 & Anchorage & $\begin{array}{l}\text { Little Campbell Creek } \\
\text { Watershed Management } \\
\text { Plan }\end{array}$ & 2007 & 18.8 & 23 & 60 & AGY & 0 & 1 & 1 & 1 & 0 & 1 & 0 & -- & -- & $\begin{array}{l}\text { Channel } \\
\text { type }\end{array}$ & 0 & 0 & 1 & 1 \\
\hline 3 & AK003 & Anchorage & $\begin{array}{l}\text { Chester Creek Watershed } \\
\text { Plan }\end{array}$ & 2005 & 24.9 & 52 & 84 & $\mathrm{CON}$ & 0 & 1 & 1 & 1 & 0 & 1 & 0 & -- & -- & $\begin{array}{l}\text { Channel } \\
\text { type }\end{array}$ & 1 & 0 & 0 & 0 \\
\hline 4 & AK003 & Anchorage & $\begin{array}{l}\text { Chester Creek Watershed } \\
\text { Plan }\end{array}$ & 2014 & 31.0 & 59 & 85 & CTY & 0 & 1 & 1 & 1 & 0 & 1 & 0 & -- & -- & $\begin{array}{l}\text { Channel } \\
\text { type }\end{array}$ & 1 & 0 & 0 & 1 \\
\hline 5 & AK004 & Anchorage & $\begin{array}{l}\text { Pilot Watershed } \\
\text { Drainage Plan: Little } \\
\text { Rabbit Creek and Little } \\
\text { Survival Creek } \\
\text { Watersheds }\end{array}$ & 2008 & 7.5 & -- & 41 & $\mathrm{CON}$ & 0 & 1 & 1 & 0 & 0 & 0 & 0 & -- & $\begin{array}{l}\text { HEC- } \\
\text { HMS }\end{array}$ & -- & 0 & 0 & 1 & 1 \\
\hline & AK005 & Anchorage & Potter Creek & 2008 & 4.3 & & & & & & & & & & & & & & & & & \\
\hline 6 & AL001 & ALOA & $\begin{array}{l}\text { Mill Creek Watershed } \\
\text { Management Plan }\end{array}$ & 2010 & 24.8 & -- & 50.7 & ORG & 0 & 0 & 0 & 1 & 1 & 1 & 1 & STEPL & -- & -- & 1 & 1 & 0 & 1 \\
\hline 7 & AL003 & $\begin{array}{l}\text { Cullman } \\
\text { County }\end{array}$ & $\begin{array}{l}\text { Watershed Plan and } \\
\text { Environmental Impact } \\
\text { Statement for Watershed } \\
\text { Protection and Flood } \\
\text { Prevention }\end{array}$ & 1976 & 18.4 & -- & 6 & CTY & 0 & 1 & 1 & 0 & 0 & 0 & 0 & -- & -- & -- & 0 & 0 & 0 & 1 \\
\hline 8 & AL004 & ALOA & $\begin{array}{l}\text { Parkerson Mill Creek } \\
\text { Watershed Management } \\
\text { Plan }\end{array}$ & 2010 & 9.3 & -- & 43 & UNI & 0 & 1 & 0 & 1 & 1 & 1 & 1 & STEPL & -- & BEHI & 1 & 1 & 0 & 0 \\
\hline
\end{tabular}

